\title{
Oriented Decoration in Metal-Functionalized Ordered Mesoporous Silicas and Their Catalytic Applications in the Oxidation of Aromatic Compounds
}

\author{
Shijian Zhou ${ }^{\dagger}$, Fu Yang ${ }^{\dagger}$, Bangbang Wang, Hang Su, Kangchao Lu, Yun Ding, Kai Lei, Man Xu, \\ Bo Shao, Yun Wang and Yan Kong * \\ State Key Laboratory of Materials-Oriented Chemical Engineering, College of Chemical Engineering, \\ Nanjing Tech University, Nanjing 210009, China; zshijian@njtech.edu.cn (S.Z.); fyang0912@126.com (F.Y.); \\ Miamasvinjia@126.com (B.W.); njsuyh@njtech.edu.cn (H.S.); lukangchao150@163.com (K.L.); \\ dingyun0901@njtech.edu.cn (Y.D.); Kail23@njtech.edu.cn (K.L.); XM544308155@163.com (M.X.); \\ shaobo256@163.com (B.S.); wangy_1012@163.com (Y.W.) \\ * Correspondence: kongy36@njtech.edu.cn; Tel./Fax: +86-25-8358-7860 \\ + These authors contributed equally to this work.
}

Received: 22 December 2017; Accepted: 7 February 2018; Published: 13 February 2018

\begin{abstract}
Ordered mesoporous silicas (OMSs) attract considerable attention due to their advanced structural properties. However, for the pristine silica materials, the inert property greatly inhibits their catalytic applications. Thus, to contribute to the versatile surface of OMSs, different metal active sites, including acidic/basic sites and redox sites, have been introduced into specific locations (mesoporous channels and framework) of OMSs and the metal-functionalized ordered mesoporous silicas (MOMSs) show great potential in the catalytic applications. In this review, we first present the categories of metal active sites. Then, the synthesized processes of MOMSs are thoroughly discussed, in which the metal active sites would be introduced with the assistance of organic groups into the specific locations of OMSs. In addition, the structural morphologies of OMSs are elaborated and the catalytic applications of MOMSs in the oxidation of aromatic compounds are illustrated in detail. Finally, the prospects for the future development in this field are proposed.
\end{abstract}

Keywords: oriented decoration; metal-functionalized OMSs; organic groups; structural morphology; oxidation of aromatic compounds

\section{Introduction}

Owing to the outstanding structural properties of large surface area and pore volume, and well-defined pore system, ordered mesoporous silicas (OMSs) have been paid much attention in the numerous applications of catalysis, adsorption, separation, sensing, medical usage, ecology, and nanotechnology [1-7]. Besides, due to the inert property of the pristine silica, the introduction of metal active sites could effectively induce the properties of optical, electronic, magnetic, catalytic, etc., in OMSs, and, consequently, the existence state of metal active sites directly determines the performance of these modified materials.

However, for most metal-based OMS catalysts, metal active sites are mainly immobilized on the outside surface, and these metal nanoparticles inevitably grow into large crystallites $[8,9]$. Thus, the loss of active surface area by the growth of metal nanoparticles would be mainly responsible for the deactivation of metal-supported OMSs catalysts [10]. To some extent, the particle growth could be alleviated by adjusting the metallic properties of size [11], composition [12] and especially interaction with the support [13]. Generally, for the application of OMSs as the support to fabricate the 
metal-functionalized catalysts, as shown in Figure 1, there are four immobilization routes: covalent bonding, adsorption, ion-pair formation, and entrapment [14,15]. Obviously, the interactions between metal active sites and support are different when using different immobilization methods, and the strong interactions by the chemical bonding of covalent linkage and electrostatic interactions would make more stable metal-functionalized OMSs than that by the physical adsorption. In this case, the dispersion of active metals is promoted in the catalysts and the agglomeration is highly inhibited during the reaction process. Besides, considering the unique pore system and versatile framework of OMSs, the metal active sites could be directly introduced into specific locations (including mesoporous channels and framework) instead of the outside surface, which would further strengthen the interactions between metal active sites and support. Specifically, by the confinement effect of mesoporous channels, the size of active metals would be limited and the interaction with the silica wall is highly promoted, whereas the substitution of silicon will result in a relatively homogeneous incorporation of heteroatoms in OMSs materials [16].

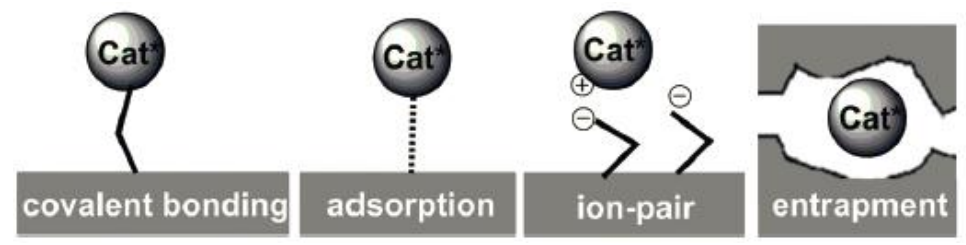

Figure 1. Schematic representation of four immobilization methods for the fabrication of metalfunctionalized OMSs. Reproduced from Reference [14] with permission of The Royal Society of Chemistry.

For modifying the OMSs through covalent linkage and electrostatic interactions, two main methods of grafting (post-synthesis) and co-condensation (direct-synthesis) are explored. Grafting is commonly used to immobilize the organometallic complexes on the silica surface by the covalent linkage, which is much more stable than that obtained by physical adsorption. However, in this method, the distribution and concentration of organometallic complexes are highly influenced by the reactivity of the complexes and their accessibility to surface silanols [17]. By grafting within mesoporous channels, the pore size of OMSs is relatively decreased, leading to the blocking of diffusion and the reduction of catalytic efficiency. Compared with the grafting method, co-condensation is another method to functionalize OMSs, in which the organometallic complexes are hydrolytically condensed with silica resources. This direct synthetic pathway provides more advantages in metal-functionalized OMSs, such as short preparation time, the homogeneous distribution of organometallic complexes, increased metal loading amount, suitable pore size and pore arrangement. Furthermore, due to the mismatch for the incorporation of transition metal ions and the formation of silica, the control of morphology and structure of OMSs would be more difficult $[18,19]$. For example, nonionic surfactants (such as P123 and F127) have been widely used as templates for the fabrication of HMS (Hexagonal Mesoporous Silica), normally in strongly acidic conditions [20]. However, highly acidic media are not ideal for incorporation of transition metal ions due to the large solubility of Si-O-M species. With the help of organic groups, the milder media would be supplied to anchor the active metals and may solve this problem. Although some reviews have summarized the metal-functionalized mesoporous silicas $[14,17,21,22]$, it is still worth providing a review of the ordered mesoporous silicas functionalized through covalent linkage and electrostatic interactions by organic groups.

In this review, we provide an overview of the oriented decoration of metal-functionalized ordered mesoporous silica and their applications in the oxidation of aromatic compounds. Attributed to the oriented decoration, the metal active sites would be directly introduced with the assistant of the organic groups into the specific locations including mesoporous channels and framework of OMSs. In the first part, we briefly present the categories of metal active sites. Then, the oriented decoration of metal active sites in OMSs have been illustrated and the structural morphologies of OMSs are 
discussed. Finally, the applications of MOMSs in the oxidation of aromatic compounds are elaborated and the prospects for future development in this field are proposed.

\section{The Categories of Metal Active Sites}

For mesoporous silica materials, the presence of neutral framework and the absence of any acidic, basic or redox property greatly limit their catalytic applications. Therefore, for the performance improvement, different kinds of metal elements are introduced and sorted into two main categories, acidic-basic and redox metal active sites.

\subsection{Acidic-Basic Metal Active Sites}

\subsubsection{Acidic Active Sites}

Due to the silanol groups on the surface, all of the siliceous materials present extremely low acidity. In comparison, zeolite materials own large amount of acidity causing by the presence of $\mathrm{AlO}_{4}$ instead of $\mathrm{SiO}_{4}$ in pristine silica. Similarly, to create the acidity, many acidic metal species have been introduced in the mesoporous silica, and the common used acidic metal species are the IIIA elements such as $\mathrm{Al}, \mathrm{Ga}$, and In. Wang et al. [23] obtained $\mathrm{Al}_{2} \mathrm{O}_{3} @$ SBA-15 composites by coating the $\mathrm{Al}_{2} \mathrm{O}_{3}$ inside the mesopores, in which abundant surface silanol are grouping in the vicinity of $\mathrm{Al}$ atoms as $\left\{\mathrm{SiOH}, \mathrm{Al}^{\mathrm{IV}}\right\}$ in the mesoporous channels, leading to the production of Brönsted acid sites on the interface of alumina and SBA-15. This hydrophilic inner surface facilitates the dispersion of Pt particles and the metal-support interaction is significantly strengthened, thus the $\mathrm{Pt} / \mathrm{Al}_{2} \mathrm{O}_{3} @ S B A-15$ catalysts are proven to be highly efficient in the asymmetric hydrogenation of ethyl pyruvate. In addition, from the results of Jiménez-López's group [24], after doping the aluminum in the MCM-41, the strong acid sites of both Brönsted and Lewis acid sites are produced, making high catalytic activity for the dehydration of glucose to HMF. However, in this catalyst, due to the existence of amorphous alumina, some acid sites with low strength are also presented, which would block the pores where the most acidic centers are located, leading to a reduced catalytic activity. Zepeda et al. [25] synthesized Ga-modified Ti-HMS materials with varying Ga content. The incorporation of Ga creates both Brönsted and Lewis acid sites, and is preferential to the population of Brönsted acid sites. With the increment of Ga content, the Brönsted/Lewis acidity ratio is linear for the Ti-HMS-xGa catalysts.

In addition to the elements from IIIA group, the weakly basic metals such as $\mathrm{Fe}, \mathrm{Ti}$, W, etc., could also act as the acidic centers in the OMSs. Chen et al. [26] investigated the acidic property of Ti-SBA-15 mesoporous materials and further compared with ZSM- 5 zeolite. Since the Ti species exist as the tetrahedral $\mathrm{Ti}^{4+}$, Lewis acid property is obtained in Ti-SBA-15, while the $\mathrm{Al}^{3+}$ species in $\mathrm{ZSM}-5$ are related to both Brönsted and Lewis acid sites. Moreover, the $\mathrm{Ti}^{4+}$ species are less acidic than $\mathrm{Al}^{3+}$ species in the framework. Aziz et al. [27] used $\mathrm{WO}_{3}$ supporting silica mesoporous-macroparticles as a heterogeneous acid catalyst. The incorporation of tungsten species into the framework brings both Brönsted and Lewis acid sites, and the formation of monolayer $\mathrm{WO}_{3}$ on the surface is beneficial for the improvement of Lewis acid sites, while higher Brönsted acid sites content would be generated by the agglomeration of these $\mathrm{WO}_{3}$ into bulk particles. Zakharova et al. [28] obtained Ti, $\mathrm{Zr}$ and Al-supported mesoporous silica, and found that the formation of strong Lewis acidity is attributed to these metal species appended to the silanol groups on the surface of mesoporous silica; in addition, the Lewis acidity is not a function of metal loading but rather of the metal nature.

\subsubsection{Basic Active Sites}

The basic metal active sites are less discussed compared with acid sites. In general, to introduce the basic active sites in the OMSs, the alkali metals ( $\mathrm{Li}, \mathrm{Na}, \mathrm{K}$, etc.) and alkaline earth metals (Be, $\mathrm{Mg}$, $\mathrm{Ca}$, etc.) attract a lot of attention [29-36]. Cano et al. [37] developed the solid of SBA-15 with alkali metals $(\mathrm{Li}, \mathrm{K}$, and $\mathrm{Cs})$ that generate basic sites of weak and moderate strength. The $\mathrm{CO}_{2}$ molecules adsorb on alkali and/or alkaline earth metals by different species of unidentate carbonates, bidentate 
carbonates and bicarbonate (as shown in Figure 2) [38,39]. These different species are relevant with different status of the oxygen atoms, in which, isolated $\mathrm{O}^{-2}$ presenting on edges and vertices of small crystals are necessary for the formation of unidentate carbonates, the pairs of $\mathrm{M}^{+\mathrm{n}}-\mathrm{O}^{-2}$ on Brönsted basic sites are facilitated to the formation of bidentate carbonates, bicarbonate species, which are the most liable in three species, correspond to the superficial $\mathrm{OH}$ groups. The strength order of superficial basic sites is proposed as follows: isolated $\mathrm{O}^{-2}>\mathrm{M}^{+\mathrm{n}}-\mathrm{O}^{-2}$ pairs $>\mathrm{OH}$ groups. The negative partial charge of oxygen anions will determine the basicity of the oxide, and the value will decrease with the increase of atomic mass. In the alkali-doped SBA-15 materials, the order of basic strength and types of sites is $\mathrm{Li}>\mathrm{Cs}>\mathrm{K}$.

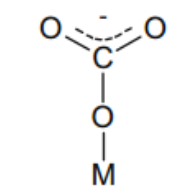

Monodentate carbonate

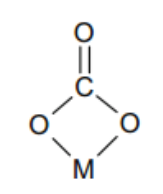

Bidentate carbonate<smiles>[M]OC(=O)O</smiles>

Bicarbonate

Figure 2. $\mathrm{CO}_{2}$ molecules adsorb on alkali and/or alkaline earth metals by different species. Reproduced from Ref. [37], Copyright 2017, with permission from Springer.

Sun et al. [33] proposed the schematic process of the formation of basic sites on Ca/SBA-15 by the methods of one-pot synthesis and impregnation. By the presence of large amount of superficial $\mathrm{OH}$ groups, the well-dispersed $\mathrm{Ca}^{2+}$ in the channels through the one-pot synthesis procedure will react with $\mathrm{Si}-\mathrm{OH}$ to form $\mathrm{CaSiO}_{3}$ species at $550{ }^{\circ} \mathrm{C}$, and then generates the medium basic sites. While the strong basic sites are formed on the surface of isolated $\mathrm{CaO}$ species. In addition, Zhang et al. synthesized Mg-modified SBA-15 catalyst with different content of $\mathrm{MgO}$. The $\mathrm{CO}_{2}-\mathrm{TPD}\left(\mathrm{CO}_{2}\right.$-Temperature Programmed Desorption) results proved that the addition of $\mathrm{Mg}$ increased the amount of basic sites which was responsible for the enhanced catalytic activity, and these moderate basic sites favored the inhibition of carbon formation during the reaction [40].

\subsection{Redox Metal Active Sites}

To introduce the redox active sites in the OMSs, various transition metals have been chosen. Tušar et al. [41] prepared solid redox catalysts of mesoporous MnMCM-41 and MnMCM-48, in which the manganese species exist as a distorted tetrahedral coordination of $\mathrm{Mn}^{3+}$ in the framework and the pore architecture of mesoporous silica. The particular coordination of manganese species and the large pore size in the mesoporous silica are beneficial for the conversion of ethyl- and 4-methylethylbenzene reaction. Liang et al. [42] used the coprecipitation method to get the iron-incorporation mesoporous silica that the iron species are acted as two types of active sites, iron atoms in the framework of tetrahedral coordination environment and the extra-framework small oligometric iron species. The iron species in the framework are favorable for the activity of phenol hydroxylation, while the extra-framework species accelerate the deep oxidation to produce more tars during the reaction. Similarly, by the evaporation induced self-assembly (EISA) method, Zhu's group [43] introduced cobalt species in Co-SBA-16 as isolated $\mathrm{Co}$ (II) species in tetrahedral coordination, most of them exist as single framework $\mathrm{Co}^{2+}$ sites while other isolated $\mathrm{Co}(\mathrm{II})$ species are located on the surface of SBA-16. The framework and surface $\mathrm{Co}^{2+}$ species in the Co-SBA-16 catalysts both play important roles in the hydroxylation of benzene to phenol.

Moreover, to further improve the redox property of the catalysts, the addition of second transition metal species is considered to be an effective solution. Hu et al. [44] obtained $\mathrm{Cu}_{x}$-V-HMS catalysts by incorporating different amount of $\mathrm{Cu}$ into the V-HMS catalysts. During the reaction of benzene hydroxylation, the addition of copper in the V-HMS catalysts is favorable for the adsorption of 
reactants and the redox ability of vanadium species, which would strongly promote the catalytic activity. Shen et al. [45] incorporated different transition metals of $\mathrm{Fe}, \mathrm{Co}$, and Ni into the framework of MCM-41 and further used in the photocatalytic hydrogen production. Due to the ligand-to-metal charge-transfer (LMCT) excitation of metallic centers in the framework, Fe-MCM-41 catalyst displayed high photocatalytic activity. While introducing another metal of Ni into the framework, the oxo-bridged bimetallic redox sites are formed in the Fe/Ni-MCM-41 catalysts by the effect of metal-to-metal charge-transfer (MMCT) excitation, and this synergistic effect between $\mathrm{Fe}$ and $\mathrm{Ni}$ is responsible for the enhanced catalytic activity. Typically, Fe-based catalysts have been investigated to be the efficient catalysts for the Fenton oxidations, and by the co-effect of Fe with additional transition metals $(\mathrm{Cu}, \mathrm{Ce}$, etc.), the generation of highly active hydroxyl radicals from hydrogen peroxide would be proceeded. In our former research [46], the $\mathrm{Cu}-\mathrm{Fe}$ decorated anionic surfactant-templated mesoporous silica (CuFe/AMS) is prepared and used as Fenton-like catalysts in the degradation of methylene blue. The transformation of $\mathrm{Fe}^{3+} / \mathrm{Fe}^{2+}$ and $\mathrm{Cu}^{2+} / \mathrm{Cu}^{+}$is the critical step in the overall reaction process which is stimulated by $\mathrm{H}_{2} \mathrm{O}_{2}$, and this step is beneficial for the release of $\bullet \mathrm{OH}$ radicals, leading to the improvement of catalytic activities.

\section{The Introduced Locations of Metal Active Sites in the OMSs}

Contributed to the unique characters of mesoporous structure and versatile framework of silicate composites, the metal active sites could not only be just deposited on the surface, but also be introduced to the specific locations in the OMSs, including framework and mesoporous channels. In this case, the metal active sites are correlated by chemical force instead of physical force in the OMSs, and thus the interaction between active sites and support is strengthened, the metals are highly dispersed and the agglomeration and sintering of the metal species are correspondingly inhibited. There are many strategies such as co-hydrolysis, template ion-exchange, solvent induced evaporation, grafting, and so on, achieving this located process. However, the introduction of metal active sites with the assistant of organic groups could be considered as the most convenient and efficient method, in which the active sites are anchored by the organic groups and then being placed in the specific locations.

\subsection{In the Mesoporous Channels of OMSs}

Mesoporous silica is well-known for its advanced properties of high specific surface area, high porosity and well-defined pore system, which are ideal characteristics as molecules reaction zone [47-50]. Besides, due to the narrow pore size distribution, the growth of metal particles will be significantly limited in the confined channels. By means of synergetic confinement effect, the interaction between metals and silicon wall is strengthened and the dispersion of these metals is highly promoted in the channels, thus much more quantized active sites are produced [51-53]. In the traditional impregnation method, the metal species could be introduced in the channels of mesoporous silica, but the interaction between metal species and silicon wall is weak under this circumstance, therefore, the metal species trend to migrate out of the pore channels and aggregate into bulk particles in the calcining process [54]. In comparison, the forceful metal-support interaction and confinement effect could efficiently stabilize the metal species to prevent their migration and aggregation even diffusion out of mesopores. The methods including post- and in-situ synthesis with the assistant of organic groups are correspondingly used to introduce the metal active sites in the mesoporous channels of OMSs.

\subsubsection{Post-Synthesis Method}

For the post-synthesis of grafting method, many reviews have been summarized [55-58], in which the material of mesoporous silica was previously prepared, and then the metal-functional silane coupling agents are grafted on the inner surface of the channels. For example, Ursachi et al. [59] stabilized the nanosized iron oxide inside the pore system of MCM-41. MCM-41 was firstly functionalized by the amino groups of 3-aminopropyltrimethoxysilane (APTES), and then the iron 
species were introduced by wet impregnation technique. The post-grafting method has been used to obtain highly dispersed heterogeneous composites, but low loading amounts still limit its application. Moreover, the mesopores in the OMSs might also be partially blocked by this method, causing the inhibition of mass transfer and diffusion process. Zhang et al. [60] developed an ultrasonic post-grafting method to fabricate the $\mathrm{CuO} / \mathrm{SBA}-15$ composite catalysts, the external surface of SBA-15 was firstly protected by the trimethylchlorosilane (TMCS) and then the inner surface was modified by the 3-aminopropyltriethoxysilane (APTES). By the grafting of TMCS, the growth of copper particles is inhibited due to the lack of silanols or other polar/coordinating groups on the outer surface. The grafting of APTES can improve the ability to anchor copper ions on the internal surface of the channels (Figure 3). With this method, the loading amount and dispersion on the inner surface of the channels in SBA-15 could be successfully promoted.

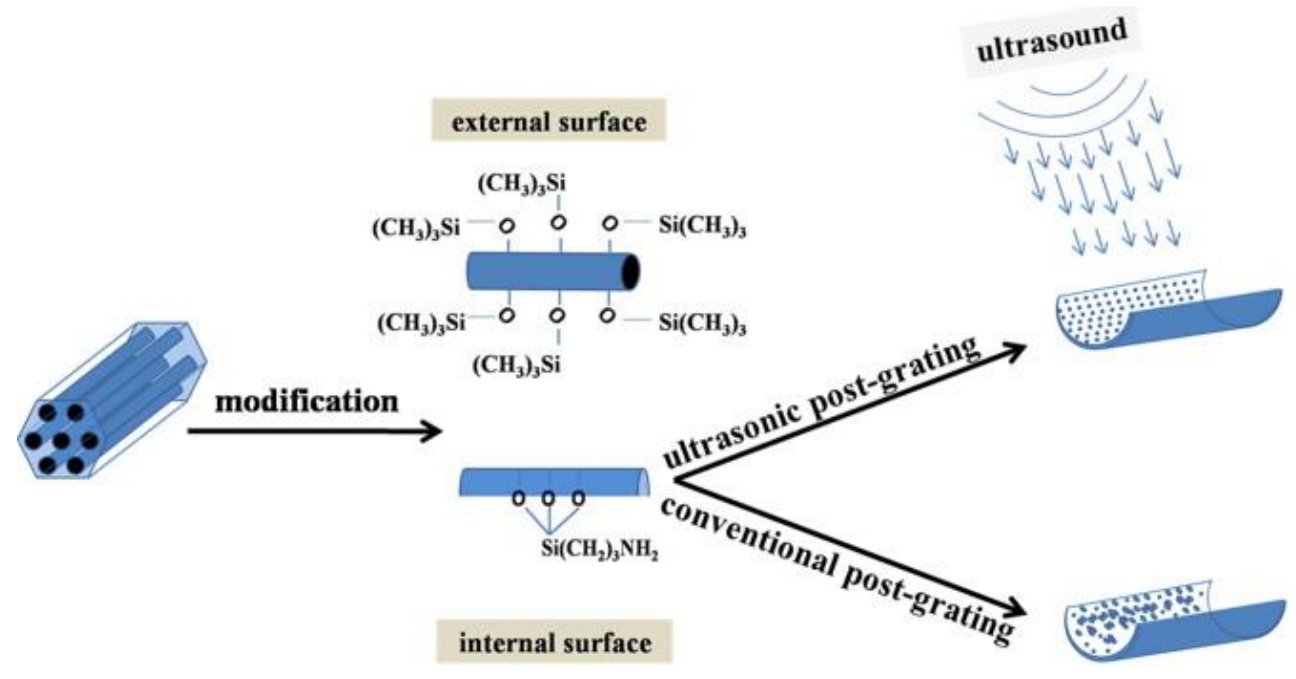

Figure 3. Schematic illustration of the representative synthesis procedure of CuO/SBA-15. Reprinted from Ref. [60], Copyright 2013, with permission from Elsevier.

In addition, the template ion-exchange (TIE) method could be considered as another effective post-synthesis method. Kowalczyk et al. [61] deposited the transition metals of $\mathrm{Cu}$, Fe, and $\mathrm{Mn}$ into the meso-channels of MCM-41 by TIE method. As shown in Figure 4, during the exchange process, the bonds of Si-O-TM would be formed according to the following equation:

$$
\mathrm{nSi-} \mathrm{O}^{-} \mathrm{S}^{+}+\mathrm{TM}^{\mathrm{n}+} \rightarrow \mathrm{n}\left(\mathrm{Si}-\mathrm{O}^{-}\right) \mathrm{TM}^{\mathrm{n}+}+\mathrm{nS}^{+}
$$

where $\mathrm{S}^{+}$stands for alkylammonium cations, $\mathrm{TM}$ stands for the transtion metals, and $\mathrm{n}$ stands for the oxidation state.

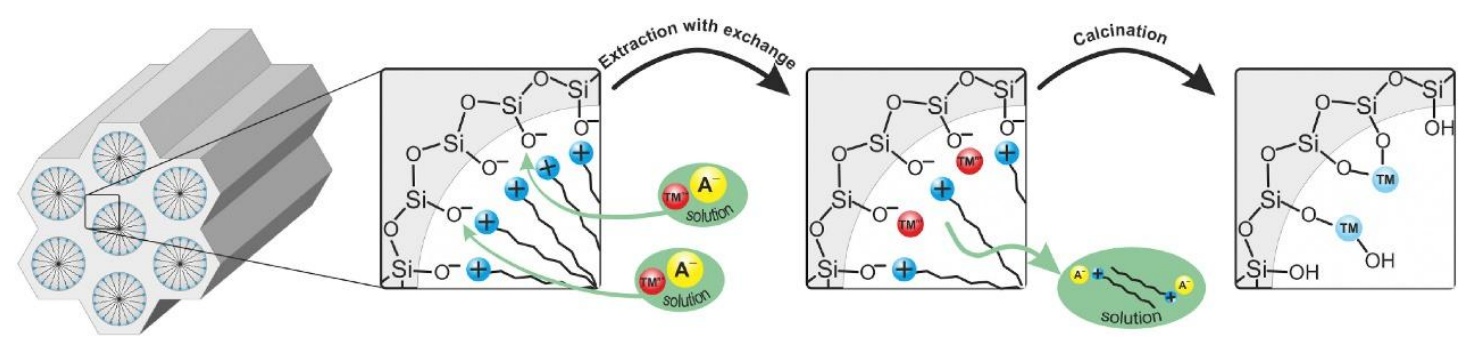

Figure 4. Schematic presentation of the procedure of transition metal deposition on the surface of as-prepared MCM-41 by TIE method: $\mathrm{TM}^{\mathrm{n}+}$, transition metal cations; and $\mathrm{A}^{-}$, anions. Reprinted from Ref. [61], Copyright 2017, with permission from Elsevier. 
However, by the deposition of copper species in the channels through this TIE method, nanorod $\mathrm{CuO}$ crystallites were formed on the MCM- 41 surface, while this aggregation of copper species to $\mathrm{CuO}$ crystallites would be fully inhibited by simultaneous deposition of iron/manganese together with copper. Besides, the TIE method caused partial leaching of organic surfactants during the synthetic process, and thus lower amount of heat would be produced in the subsequent calcination step by the exothermal combustion of the residual organic complexes. Therefore, the sintering of the deposited metal species and the shrinking of the porous structure might be relatively limited.

Recently, Cirujano et al. [62] prepared the hybrid materials of $(\mathrm{Zr}) \mathrm{UiO}-66\left(\mathrm{NH}_{2}\right) / \mathrm{SiO}_{2}$ in which the metal-organic framework (MOF) nanocrystals of $(\mathrm{Zr}) \mathrm{UiO}-66\left(\mathrm{NH}_{2}\right)$ were confined in the mesoporous channels of SBA-15. By this method, the size of MOF crystals is down to a few nanometers by confining within the mesoporous silica, causing the huge increase of the concentration of coordination vacancies at the outer surface of crystal. In addition, owing to the protection of the silica matrix, these MOF nanocrystals display high catalytic activity and stability. For the transformation of steroids and generation of pharmaceutically interesting compounds, the MOF nanocrystals confined in mesoporous silica allows for multiple reuses of the catalyst without significant leaching of the active sites. Furthermore, due to the increased catalytic activity and mechanism stability, this hybrid material could be considered as a potential catalyst in the commercial and industrial application.

\subsubsection{Direct-Synthesis Method}

As the synthesis of ordered mesoporous silica, the surfactant-directed assembly method is widely used. Besides, the cationic $\left(\mathrm{S}^{+} \mathrm{I}^{-}\right)[63]$, anionic $\left(\mathrm{S}^{-} \mathrm{X}^{+} \mathrm{I}^{-}\right)[64]$ and neutral $\left(\mathrm{S}^{0} \mathrm{I}^{0}\right)$ [65] surfactant-templated pathways have been applied to prepare ordered mesoporous silica of MCM, AMS, and HMS, where $S$ stands for surfactant, $\mathrm{X}$ stands for counter-ions, and I stands for inorganic precursors.

\section{Cationic Surfactant-Templated Route $\left(\mathrm{S}^{+} \mathrm{X}^{-} \mathrm{M}^{+} \mathrm{I}^{-}\right)$}

Based on the cationic surfactant-templated route, the assembly for the formation of MCM series has been promoted by electrostatic charge-matching pathways including $\mathrm{S}^{+} \mathrm{I}^{-}$and $\mathrm{S}^{+} \mathrm{X}^{-} \mathrm{I}^{+}\left(\mathrm{S}^{+}\right.$stands for cationic surfactants; $\mathrm{I}^{-}$or $\mathrm{I}^{+}$stands for electronegative or electropositive silicates; and $\mathrm{X}^{-}$stands for counter-anions). Instead of post-grafting method, Singha et al. [66] reported a two-step process of the synthesis of Fe-containing complex onto the channel surface of MCM-41. They prepared a new chelating agent of salimHSi in advance by the mixture of APTES and salicylaldehyde, and then mixed with cetyl trimethyl ammonium bromide (CTAB) and tetraethyl orthosilicate (TEOS) to form the hybrid mesoporous materials MCM-41-salimH. Finally, the ferric chloride solution was added and the iron species were anchored on the chelating agent. During this method, the chelating agent of salimHSi was in-situ introduced in the mesoporous channels and the iron species were post-grafted on the chelating agent. In fact, during the self-assembly process, the transition metals $\left(\mathrm{M}^{+}\right)$could be directly introduced by the effect of coulomb interactions in the position between cationic surfactant micelles $\left(\mathrm{S}^{+}\right)$and silicate oligomers $\left(\mathrm{I}^{-}\right)$. To achieve this process, as the schematic mechanism shown in Figure 5, our group developed a direct templating assembly method $\left(\mathrm{S}^{+} \mathrm{X}^{-} \mathrm{M}^{+} \mathrm{I}^{-}\right)$to obtain the $\mathrm{V} / \mathrm{MCM}$ catalysts [67], which was based on the self-assembly of cationic surfactants $\left(\mathrm{CTA}^{+}, \mathrm{S}^{+}\right)$, chelating agents (citrate ions, $\mathrm{X}^{-}$), vanadyl ions $\left(\mathrm{VO}^{2+}, \mathrm{M}^{+}\right)$and silicate oligomers $\left(\mathrm{I}^{-}\right)$via electrostatic and chelating interaction. Through this method, the citrate ions $\left(\mathrm{X}^{-}\right)$were firstly absorbed on the surface of $\mathrm{CTA}^{+}$micelles $\left(\mathrm{S}^{+}\right)$by electrostatic interaction, then the vanadyl ions $\left(\mathrm{M}^{+}\right)$were subsequently anchored on their surface by chelating with citrate ions to form metallomicelles $\left(\mathrm{S}^{+} \mathrm{X}^{-} \mathrm{M}^{+}\right)$, and the electronegative silicates oligomers $\left(\mathrm{I}^{-}\right)$were finally deposited on the metallomicelles. For these catalysts, this metallization of the micelles would directly cause the surface functionalization of the silicate wall, and the vanadium oxide species in the channels exhibited a high-dispersion and gradual coverage on the pore wall with increasing vanadium concentration. 


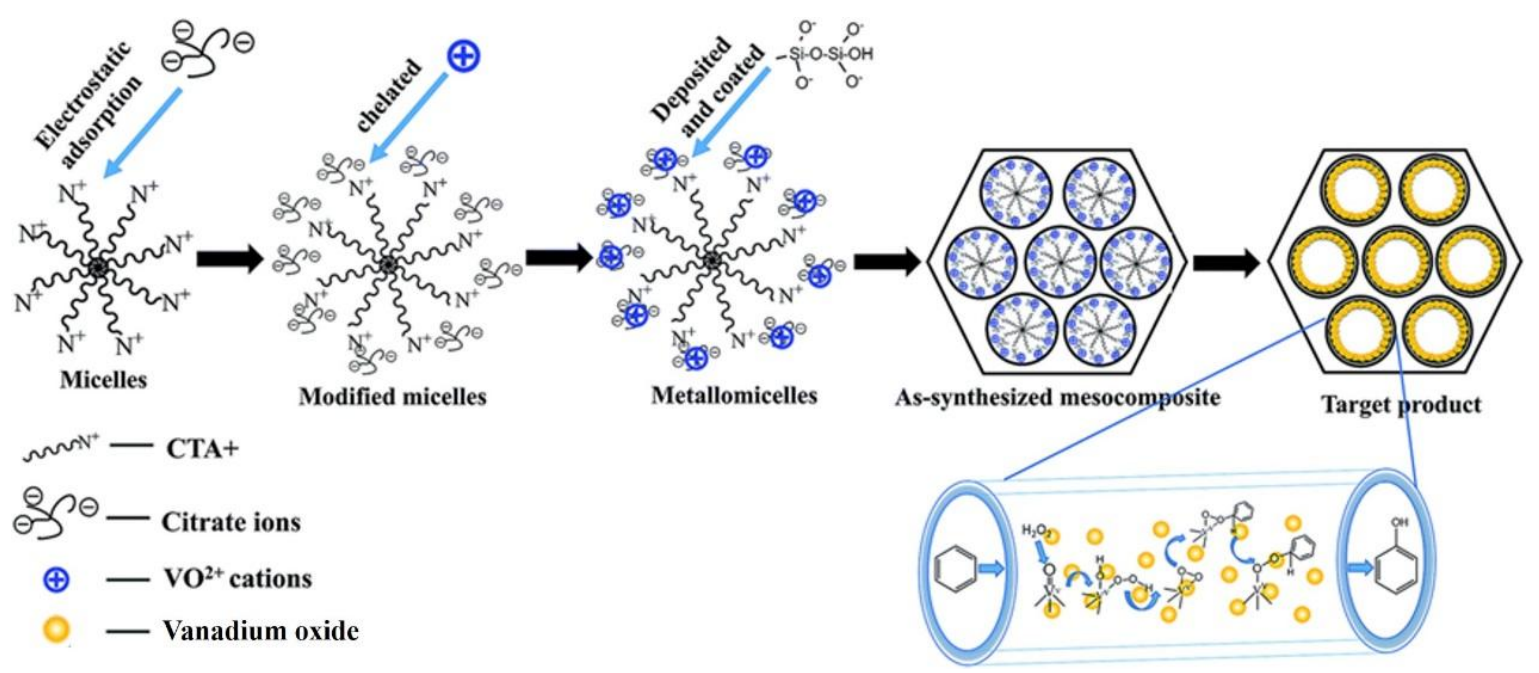

Figure 5. Schematic mechanism for material self-assembly. Reproduced from Ref. [67], Copyright 2015, with permission of The Royal Society of Chemistry.

Anionic Surfactant-Templated Route $\left(\mathrm{M}^{+} \mathrm{S}^{-} \mathrm{X}^{+} \mathrm{I}^{-}\right.$or $\left.\mathrm{S}^{-}[\mathrm{MN}]^{+} \mathrm{I}^{-}\right)$

For the anionic surfactant-templated route, the $\mathrm{S}^{-} \mathrm{I}^{+}$or $\mathrm{S}^{-} \mathrm{X}^{+} \mathrm{I}^{-}\left(\mathrm{S}^{-}\right.$stands for anionic surfactants, $\mathrm{X}^{+}$stands for counter-cations) pathway for the AMS series is proposed. In this pathway, aminosilane (e.g., 3-aminopropyltrimethoxysilane, APTES) or quaternized aminosilane (e.g., $\mathrm{N}$-trimethoxylsilylpropyl- $\mathrm{N}, \mathrm{N}, \mathrm{N}$-tributylammonium, TMAPS) are often used as co-structure directing agent (CSDA) [68]. During the self-assembly process, the positively charged amine or ammonium sites of CSDA $\left(\mathrm{X}^{+}\right)$interact electrostatically with the templating anionic surfactant micelles $\left(\mathrm{S}^{-}\right)$and the alkoxysilane sites of CSDA cocondense with the electronegative silicates $\left(\mathrm{I}^{-}\right)$[69]. Niu et al. [53] developed a one-step method for the synthesis of $\mathrm{NiO} / \mathrm{SiO}_{2}$ composites by using $\mathrm{N}$-hexadecyl ethylenediamine triacetate (HED3A) as the mesophase structure-directing agent, and also as a chelating agent binding with nickel ions. During this method, as shown in Figure 6, the nickel ions $\left(\mathrm{M}^{+}\right)$were firstly captured by the chelating agent of HED3A to form the metal-chelated complexes of micelle-like aggregates with negative surface charges $\left(\mathrm{S}^{-} \mathrm{M}^{+}\right)$. Besides, the amino groups of APTES would be protonated and transferred into cationic ammonium species $\left(\mathrm{X}^{+}\right)$when the $\mathrm{pH}$ value is lower than the $\mathrm{pK}_{\mathrm{a}}$ value of 10.6. These positively charged APTES ammonium sites were bonded with metal-chelated complexes by the electrostatic interactions and the alkoxysilane sites would be co-condensed with TEOS $\left(\mathrm{I}^{-}\right)$to assemble in the siliceous framework $\left(\mathrm{M}^{+} \mathrm{S}^{-} \mathrm{X}^{+} \mathrm{I}^{-}\right)$. In addition, they used the same method to embed the $\mathrm{ZnO}$ [52] and $\mathrm{NiO}$ [70] nanoparticles in the mesoporous channels of AMS. Similarly, in our group, this pathway of $\mathrm{M}^{+} \mathrm{S}^{-} \mathrm{X}^{+} \mathrm{I}^{-}$has also been used to embed iron [71] and copper [72] species into the channels of AMS, by using sodium $N$-lauroylglutamate $\left(\mathrm{Sar}-\mathrm{Na}, \mathrm{S}^{-}\right)$as the anionic surfactant, and APTES as co-structure directing agent $\left(\mathrm{X}^{+}\right)$. Moreover, not only monometallic ion, but also bimetallic ions could be introduced by this route. From the results of Li et al. [46], bimetallic $\mathrm{Cu}^{2+} / \mathrm{Fe}^{2+}$ are simultaneously captured by the surface amino acid head of Sar-Na to form the metallomicelles of Sar[ $\left[\mathrm{Cu}_{x} \mathrm{Fe}\right]$, and with the help of APTES as the CSDA, TEOS is hydrolyzed and deposited on the metallomicelles, resulting in the fabrication of the bimetallic $\mathrm{Cu} / \mathrm{Fe}$ functional mesocomposites. Besides, the addition of $\mathrm{Cu}$ establishes the firmer interactions between $\mathrm{Fe}$ species and silicate wall, leading to the better dispersion of Fe species in the mesochannels of AMS.

Notably, for the pathway of $\mathrm{M}^{+} \mathrm{S}^{-} \mathrm{X}^{+} \mathrm{I}^{-}$, the transition metals $\left(\mathrm{M}^{+}\right.$, positive charge) are enriched on the micelle surface of anionic surfactant $\left(\mathrm{S}^{-}\right.$, negative charge) by the electrostatic interactions, and thus the interactions between counter cations $\left(\mathrm{X}^{+}\right)$and surfactant may be partially inhibited under strong basic conditions. Gao et al. [73] developed a novel templating pathway of $\mathrm{S}^{-}[\mathrm{MN}]^{+} \mathrm{I}^{-}$ to introduce $\mathrm{FeO}_{x}$ in the channels of AMS. Fe ions would be previously coordinated on the organic 
groups of $N$-[3-(Trimethoxysilyl)propyl]ethylenediamine (APATES) to form Fe[APATES $]^{+}\left([\mathrm{MN}]^{+}\right)$, acting as the co-structure directing agent instead of protonated APTES during the synthesis process. In this case, under strong basic conditions, the protonation would be prevented by the ethylenediamine moieties on Fe[APATES] ${ }^{+}$, and the Fe[APATES] ${ }^{+}$complexes would establish the counterion-mediated interactions between the head group of anionic surfactant $\left(\mathrm{S}^{-}\right)$and silicate oligomers $\left(\mathrm{I}^{-}\right)$.

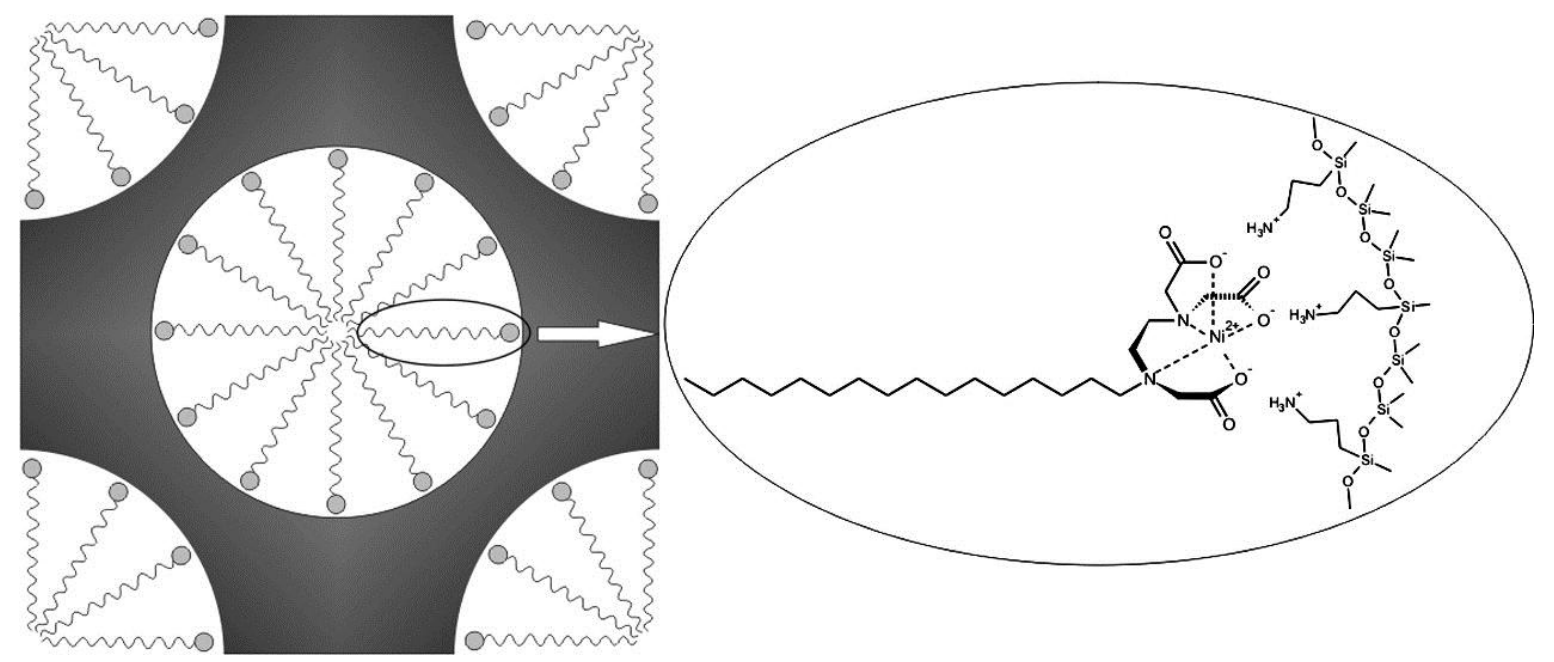

Figure 6. Schematic illustration of HED3A-assisted introduction of nickel (II) into mesopores. Reprinted from Ref. [53], Copyright 2011, with permission from Elsevier.

Neutral Surfactant-Templated Route $\left(\mathrm{S}^{0} \mathrm{M}^{+} \mathrm{I}^{-}\right)$

The assembly for the formation of HMS series is prepared by electrically neutral pathway $\left(\mathrm{S}^{0} \mathrm{I}^{0}\right)$, which depends on hydrogen bonding and self-assembly between neutral surfactants $\left(\mathrm{S}^{0}\right)$ and neutral silica species $\left(\mathrm{I}^{0}\right)$. Compared with MCM series through the pathway of $\mathrm{S}^{+} \mathrm{I}^{-}$or $\mathrm{S}^{+} \mathrm{X}^{-} \mathrm{I}^{+}$, owing to the weaker assembly forces by hydrogen bonding, the textural properties of HMS are inferior to that of the MCM series, Therefore, to amend this, a novel metal-assisted templating method of $\mathrm{S}^{0} \mathrm{M}^{+} \mathrm{I}^{-}$ has been proposed. In this method, metal cations $\left(\mathrm{Co}^{2+}[74], \mathrm{Ni}^{2+}[75], \mathrm{Ca}^{2+}[76]\right)$ are highly enriched on the interface of neutral primary amine template (dodecyl amine, DDA) through the coordinative assembly to generate the metallomicelles of $\mathrm{S}^{0} \mathrm{M}^{+}$. Instead of hydrogen bonding, these metallomicelles are matched with electronegative silicate oligomers $\left(\mathrm{I}^{-}\right)$by the counterion-mediated interactions. This metal-assisted pathway facilitates the assembly of the micelles with silicates, and the coverage and dispersion of metal oxides in the mesochannels could be regulated by adjusting the amount of metal cations on the alkylamine micelles. Besides, by encapsulating $\mathrm{CaO}$ inside the mesochannels of HMS, an unexpected strong basicity which is superior to that in the traditional CaO-based silicate composites is acquired, and thus the reaction temperature for the synthesis of dimethyl carbonate is significantly decreased. Furthermore, the bimetallic Co-Mn/HMS nanocomposites could also be obtained by this modified micelle template method [77]. As shown in Figure 7, the bimetal cations of $\mathrm{Co}^{2+}$ and $\mathrm{Mn}^{2+}$ are chemically anchored on the surface of $\mathrm{S}^{0}$ by a coordinated interaction and then assembled with electronegative silicate oligomers by electrostatic interaction. 


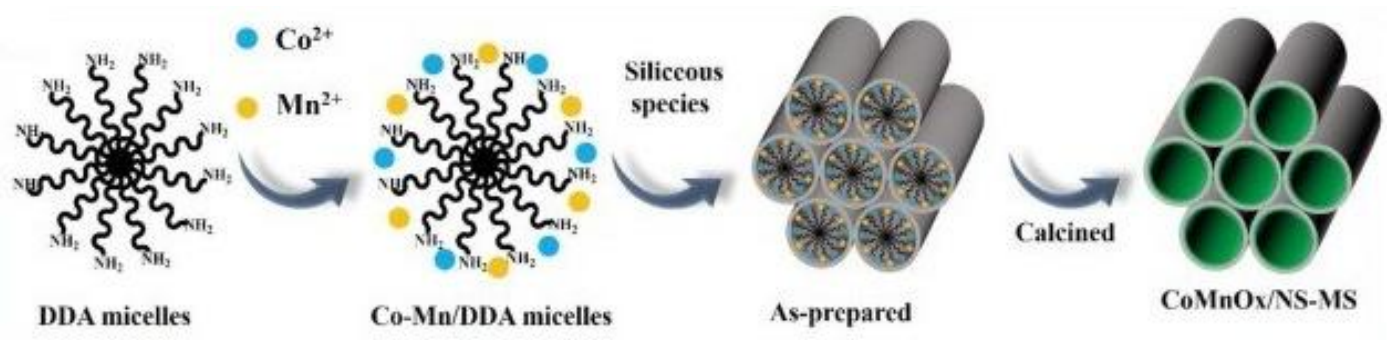

Figure 7. Schematic illustration for the synthesis of Co-Mn bimetallic oxides decorated nanospherical HMS.

\subsection{In the Framework of OMSs}

The metal active sites could also be incorporated into the mesoporous silicate matrix. To achieve this progress, many efforts have been put forward, including the direct hydrothermal method (DHT) [78,79], template ion-exchange method (TIE) [80], and wet impregnation method [81]. Particularly, in these methods, DHT is considered to be predominant due to its simplicity in the synthesis procedure, the controllable hydrolysis-condensation speed and high efficiency in incorporating the heteroatoms into the framework, while the rest are liable to induce the formation and aggregation of crystalline metal oxide on the surface of silica, causing the elution of metal active sites in the liquid-phase reactions $[49,82]$. However, the DHT method is restricted by the rigorous synthetic conditions, especially by $\mathrm{pH}$ value [83]. In this case, the interactions of metal species are complicate under different conditions and the simultaneous hydrolysis of multi-type metal precursors and silica resource is hardly to control, thus the synthesis of multi-heteroatoms incorporated silicate composites by this method is more difficult [84].

The ordered periodically mesoporous organosilicas (PMOs) attracted much attention in these years, which are hydrolytic polycondensed from bridged organosilica precursors of $\left[\left(\mathrm{R}^{\prime} \mathrm{O}\right)_{3} \mathrm{Si}\right]_{\mathrm{m}} \mathrm{R}$ $(\mathrm{m} \geq 2)$ with a structure-directing agent, making the organic groups in the framework of mesoporous silica through covalent Si-C bonds [85-87]. Through this method, the metal species could be incorporated by binding with organic groups, instead of hydrolysis with silica resource under certain $\mathrm{pH}$ value. However, generally, the functionalized PMOs contain chelating groups in the framework but the reactive functional groups in the pore channels, and the organic groups are homogeneous distributed and accessible in the final PMOs materials. Therefore, the presence of organometals and organic groups bonded with silicon in the pore channels may inevitably block the channels and induce the considerable metal leaching. From the reports of Li's group [88,89], they disclosed new PMOs series by the effects of bridge-bonded organometals and organic groups which are both incorporated in the framework of silica, denoted as $\mathrm{M}-\mathrm{PPh}_{2}-\mathrm{PMO}(\mathrm{R})$, where $\mathrm{M}$ stands for $\mathrm{Pd}^{2+}, \mathrm{Au}^{+}, \mathrm{Ru}^{2+}$, and $\mathrm{Rh}^{+}$ions, $\mathrm{PPh}_{2}$ stands for $\mathrm{PPh}_{2} \mathrm{CH}_{2} \mathrm{CH}_{2}$-ligands, $\mathrm{R}$ stands for phenyl $(\mathrm{Ph})$ or biphenyl $\left(\mathrm{Ph}_{2}\right)$ groups. During the preparation, metallic ions are firstly coordinated with $\mathrm{PPh}_{2} \mathrm{CH}_{2} \mathrm{CH}_{2} \mathrm{Si}(\mathrm{OEt})_{3}$ to form the organometal-bridged silanes, and then these organometal-bridged silanes are co-assembled with R-bridged silane and P123 surfactant, finally, the surfactant organic groups are removed by extraction. By the homogeneously incorporation of organometals and phenyl groups in the silicate framework, the well-defined ordered mesoporous channels and strong interaction between metal active sites and silica are obtained in the $\mathrm{M}-\mathrm{PPh}-\mathrm{PMO}(\mathrm{R})$. Corriu et al. $[87,90]$ used bridged organosilica of tetra- $N$-silylated cyclam (cyclam is the 1,4,8,11-tetraazacyclotetradecane which is capable of considerable binding ability toward transition metals) as the chelating agent to anchor transition metals $\left(\mathrm{Cu}^{2+}, \mathrm{Co}^{2+}\right.$, etc.). As shown in Figure 8, by the presence of P123 as the structure directing agent, the bridged organosilica is co-condensed with TEOS and organotrialkoxysilane, and thus the active metals are successfully introduced in the framework of PMO material. 


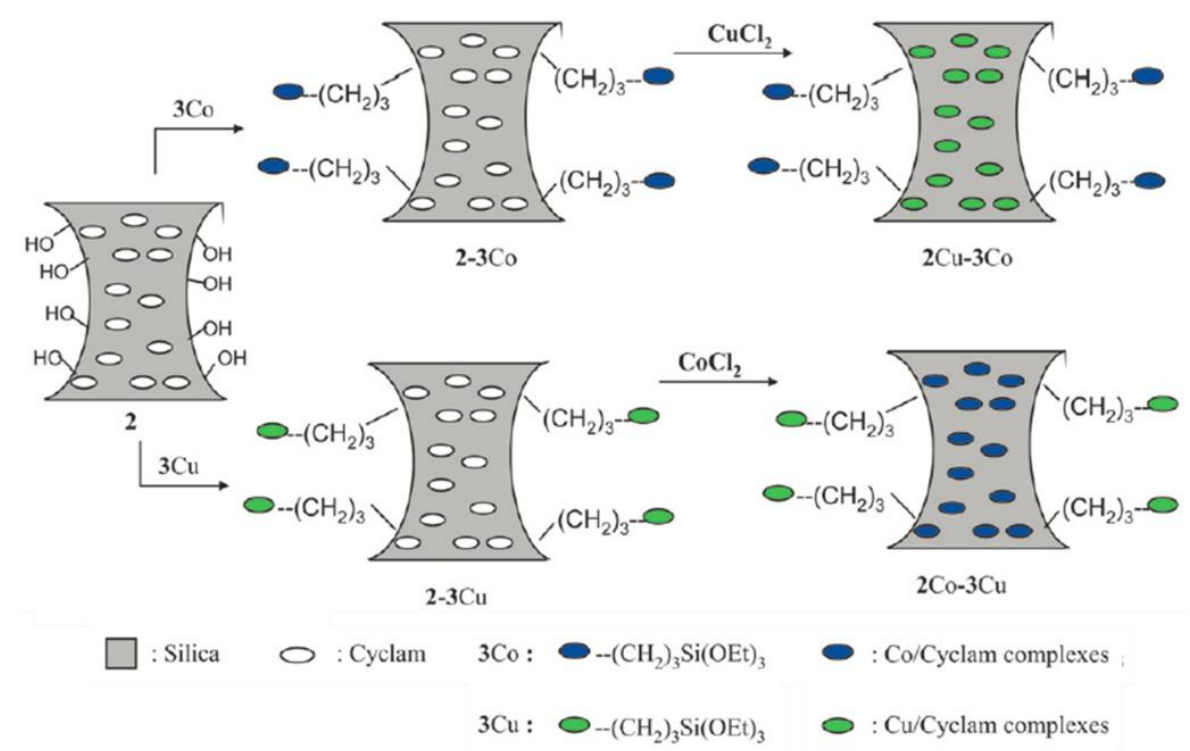

Figure 8. The schematic illustration of the grafting and incorporation process of $\mathrm{Cu} / \mathrm{Co}$ in the PMOs. Reproduced from Ref. [90], Copyright 2010, with permission of The Royal Society of Chemistry.

In our group [91], as shown in Figure 9, we obtained the V-APATES complexes through the coordination effect between $\mathrm{V}=\mathrm{O}$ and the organic group of APATES. The vanadium species were firstly coordinated with the organic group to form the functional micelles of V-APATES, then these V-APATES complexes were introduced in the framework by the direct hydrothermal synthesis. Finally, the organic template was removed by extraction to form the V-functionalized PMOs.

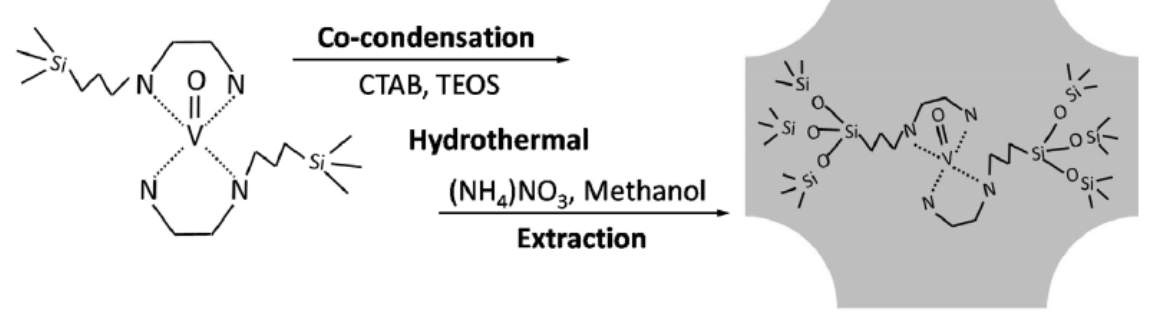

Figure 9. The schematic representation of the synthesis of V-PMO materials.

\section{Morphology and Channel Structure in OMSs}

The morphology and channel structure of OMSs afford certain effect on the heterogeneous catalytic process because of the existence of internal and external diffusion effects during the reaction process. To our knowledge, the surface structure and state of catalysts trigger the diffusing routes of reactant molecule reaching the surface of catalysts. Therefore, the morphology structure is the vital impact factor during the external diffusion-controlled process, while the channel structure and pore size of catalysts play the essential role in the internal diffusion process. In light of the morphology and channel structure of OMSs, we outline the literature on the morphology and channel structure controlled catalysts.

\subsection{Morphology}

Generally, bulky catalysts, especially for the mesoporous, silica tend to cause the mass transferring limitation. Therefore, different morphologies of mesoporous silica such as nanosphere, nanowire, nanotube and nanorod are synthesized. 


\subsubsection{Nanosphere}

From our previously report [49], as shown in Figure 10, spherical MCM-48 co-doped by Fe and V was synthesized through one-step hydrothermal method and emerged as the catalysts for the oxidation of aromatic benzene or phenol. During the catalytic process, the spherical catalysts exhibited much higher surface area which is favorable for the dispersion of the active metals, and the regularly spherical morphology would speed up the mass transferring leading to the improved catalytic activity [82,92]. In addition, Rahman et al. [18] prepared the Nb-doped HMS catalysts with different morphologies of sphere, irregular, and tube sphere-like. They found that the catalytic activity of ethylbenzene oxidation is related to the morphology of the catalysts, and the catalyst with regular spherical morphology exhibited better catalytic performance. Xie and his co-workers [93] utilized the mesoporous fiber-like nanospheres as the matrix to support manganese, and the fiber-like pore wall and cross-linking channel further promote the diffusion of reactant molecule.
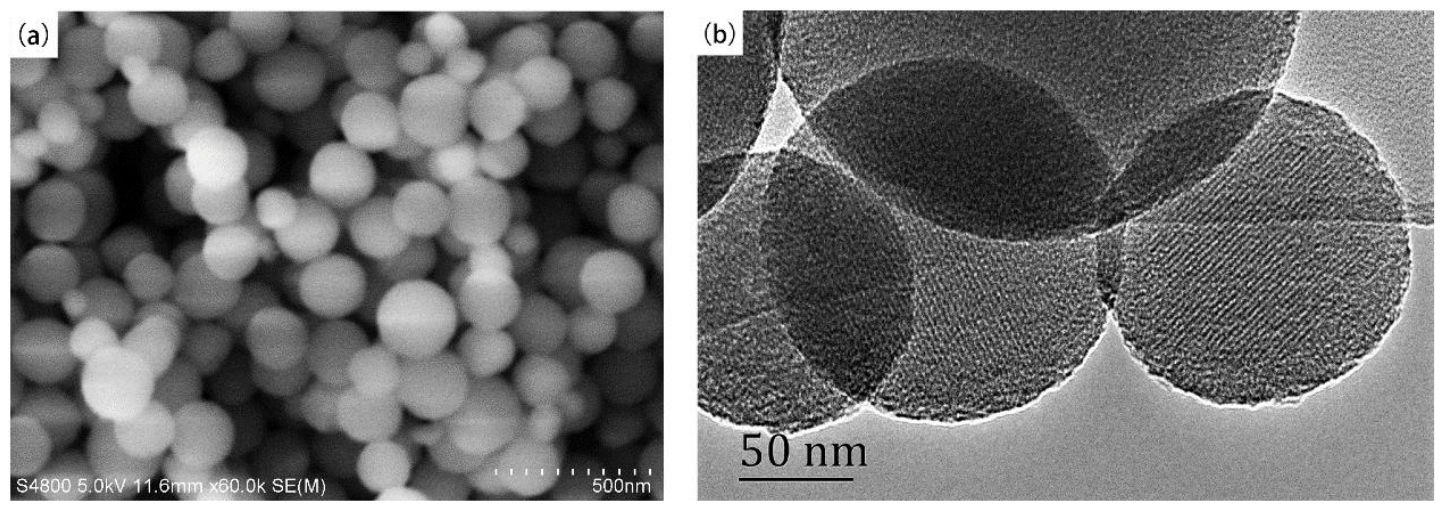

Figure 10. (a) Scanning electron microscopy (SEM) image; and (b) transmission electron microscopy (TEM) image of the spherical V-Fe-MCM-48 sample.

However, for the spherical morphology, the channel of micelle-derived mesoporous silica is closed in the center of sphere, therefore, the diffusion of reactant molecules tends to be limited. In this case, the hollow mesoporous silica spheres should be focused on due to their regular morphology, low density, and short diffusion path which permits the convenient diffusion of reactant molecules in and out of the hollow spheres [94-96]. Owing to this hollow spherical morphology, the metal-functionalized OMSs catalysts exhibit superior catalytic performances $[19,97,98]$. The reactant molecules can diffuse through the silica shell to reach the interior of hollow sphere, and thus the frequency of the contact with active metals from both outside and inside is significantly improved, leading to the acceleration of catalytic reaction. Besides, the concentration difference from inside to outside of hollow sphere is favorable to the reactant molecules continually go inside the hollow space, which ensures the sustainability of the reaction.

\subsubsection{Nanowire, Nanotube, Nanorod}

Normally, the size of spherical OMSs is several $\mu \mathrm{m}$ in diameter, so that the diffusion path of the molecules is at the range of $\mu \mathrm{m}$. This uncontrollable diffusion range partly limits the mass transportation inside the pores of OMSs. However, it is difficult to shorten the diffusion path by directly reducing the size of the OMSs materials. Therefore, by tuning the size and length of the mesoporous channels, the OMSs could be made into the various morphology of nanowire, nanotube and nanorod [99-102]. Song and his co-workers [103] produced mesoporous silica nanotubes with different morphology by hard/soft dual template and applied in the hydrogenation of cyclohexene. Compared with the MCM-41-supported catalysts, the mesoporous silica nanotubes exhibited higher yield of cyclohexane, which should be attributed to the faster mass transportation of the reactant and 
products in the shorter pores. However, they found that the yield of benzene in nanotubes catalyst is lower than that of MCM-41-supported catalyst. To explain this, it should be noted that there are two consecutive dehydrogenation steps in the generation of benzene which need longer resident time of reactant molecules during the reaction, and the short diffusion path in the mesoporous silica nanotubes will be harmful for this progress. Our group developed the mesoporous silica nanotube with the adjustable length/width ratio (Figure 11), and the ulterior function of mesoporous silica nanotube with the transition metal iron and copper was employed through one-step solubilization or doping method $[104,105]$. During the reaction process, the water solvent would compete the adsorption on the active metals with reactant molecules due to the inner hydrophilic surface of mesoporous silica nanotube. The improved inner diffusion time of reactant by the adjustable length of nanotube could effectively promote the phenol adsorption, making the enhancive catalytic activity. However, the longer diffusion time is favorable for the diffusion of hydroquinone which consequently induces the lower dihydroxybenzene selectivity. Apart from the mesoporous silica nanotube, the mesoporous silica nanowire has also been developed to obtain the hierarchical structure, which regarded as promoted reaction structure in the oxidative desulfurization [106]. Therefore, the manipulation of the size and morphology of OMSs catalysts will directly regulate the catalytic activity as well as the products distribution.

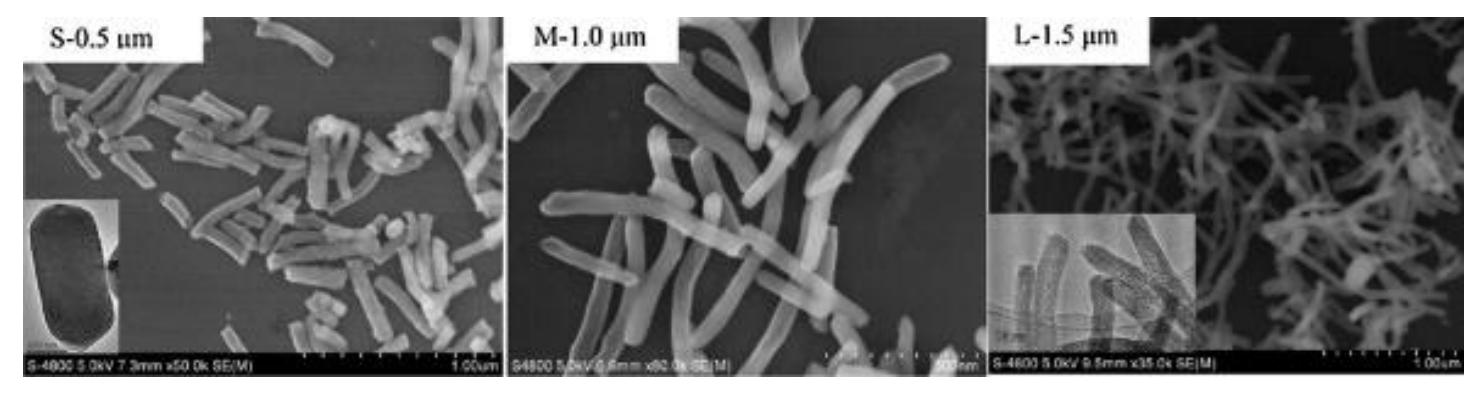

Figure 11. The controllable morphology of mesoporous silica nanotube. Reprinted from Ref. [104], Copyright 2015, with permission from Elsevier.

\subsection{Structure}

In the case of pore structure-derived mesoporous silica, the reactant molecule would undergo the different internal diffusion behaviors owing to the various internal pore structures, while the representative structures of mesoporous M41S materials are shown in Figure 12 [107]. For instance, the 2D hexagonal mesochannel could provide the parallel narrow channel for the confined two-path of diffusion including in and out of chemical molecule from the aperture. Mesoporous MCM-41 and SBA- 15 are the most widely studied in heterogeneous catalysis, and the corresponding modifications involving the doping and post-impregnation method were conducted. Chen and his co-workers obtained hierarchical mesoporous silica with 2-D hexagonal structure, and this hierarchical silica catalyst exhibited much higher reaction rate in catalytic reduction of 4-nitrophenol [108]. However, the $3 \mathrm{D}$ pore channel is more promising in heterogeneous catalysis thanks to the dominant cross-linking pores affording more random diffusion and collision behaviors with the catalytic active sites anchored on the pore wall during the reaction process [109], which is typical in the materials of SBA-16 and KIT-6. Three-dimensional interconnected pore structures are generally expected to be superior to 2-D hexagonal structured materials (with one-dimensional channels), especially in the diffusion and transportation involving bulky molecules [110,111]. Shi et al. [112] reported the hierarchical Ti-SBA-2 with ordered 3-D hexagonal mesostructure for the first time. This well interconnected pore structure is favorable for the accessibility of active sites and the diffusion of reactants and products. In addition, Peng et al. [113] found that the MCM-48 with interconnected pore network provides profitable mass transfer kinetics in competition with the unidimensional hexagonal pores in MCM-41. From the 
results of Chen's group [114], the material of Al-SBA-1 which possesses a cage-type structure with 3-D interconnected small open windows was obtained. The 3-D pore system in Al-SBA-1 is capable of resistance to pore blocking and effortless diffusion of reactant molecules, while the mass transfer is limited in the HZSM-5 catalyst. Grams et al. [115] prepared nickel-based catalysts supported on different kind of mesoporous silica including MCM-41, SBA-15, SBA-16 and KIT-6. They found that the different structure properties would considerably influence the yield of the examined reaction. The advanced 3D structure facilitates mass transfer and the number of collisions between nickel species and reaction intermediates are increased during the reaction. In addition to the pore structure, the pore size factor exerts an obvious determined impact for the reactant molecules during the diffusing process [71]. Typically, our previous works [72] demonstrated when the cluster-like $\mathrm{CuO}$ species were introduced into mesopores of mesoporous silica, as shown in Figure 13, the enriched micropores emerge due to the occupation of $\mathrm{CuO}$ in the channels and enhance the collision and contact of reactant molecules with the catalytic active $\mathrm{CuO}$ species on the pore wall.

a)

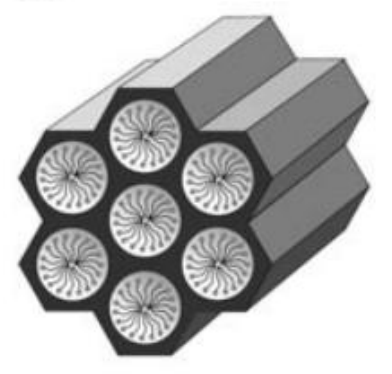

b)

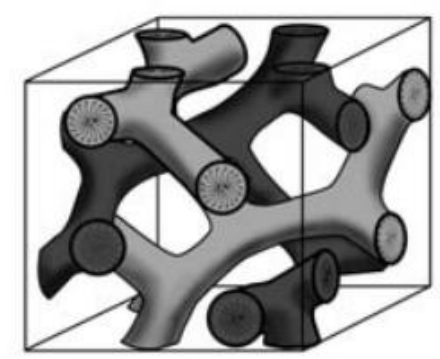

c)

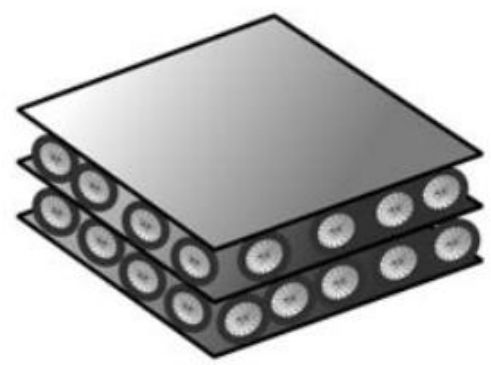

Figure 12. Structures of mesoporous M41S materials: (a) MCM-41 (2D hexagonal, p6mm); (b) MCM-48 (3D cubic, Ia3d); and (c) MCM-50 (lamellar, p2). Reproduced from Ref. [107], Copyright 2006, John Wiley and Sons.

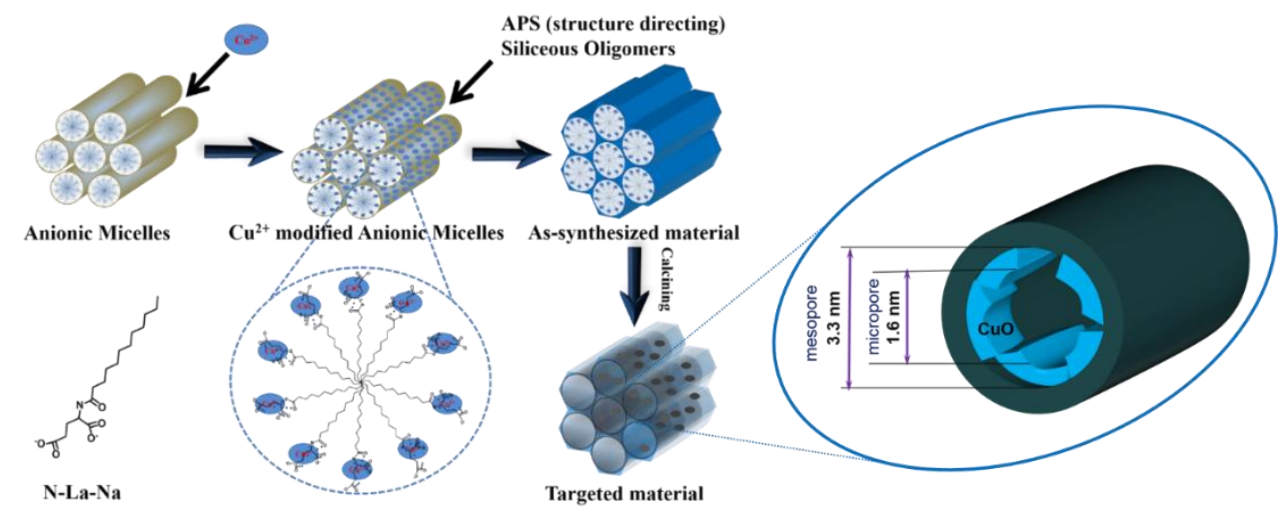

Figure 13. The tailored pore channels in CuO-based mesoporous silica through the anionic templateinduced method.

\section{OMSs in the Oxidation of Aromatic Compounds}

Transition metal modified mesoporous silicas have emerged as the promising oxidation catalysts in the case of the oxidation of aromatic compounds, which ascribe to the superior dispersion and exposure of transition metal atom on the surface of mesoporous silica. These reactions include the oxidation of benzene, styrene, ethylbenzene, phenol, methylbenzene and benzyl alcohol, among others. 


\subsection{Benzene Oxidation}

The direct oxidation of benzene towards phenol attracted the widest attention thanks to its simple and firsthand process, which could alternatively replace traditional three-step cumene process generally suffered from high energy consumption, formation of by-product acetone and low phenol yield $(<5 \%)$. Therefore, the involved direct hydroxylation of benzene has been intensively studied based on the transition metal modified mesoporous silica. Mohammadi et al. [116] reported the Fe modified SBA-16 for the direct hydroxylation of benzene with $11.7 \%$ conversion and $96.4 \%$ selectivity towards phenol, and Figure 14 shows a reaction mechanism of the catalytic benzene hydroxylation by $\mathrm{H}_{2} \mathrm{O}_{2}$ in the presence of Fe/SBA-16. However, this result seems to be undesirable compared to other functional mesoporous catalysts. For instance, He et al. [117] demonstrated that V functionalized SBA-15 showed superior catalytic activity (34.1\% conversion and $93.2 \%$ selectivity to phenol) through the functional organic silane (dichlorodimethylsilane) modification to improve the wettability of mesoporous surface. The functional organic group was beneficial to the affinity of reactant molecules with catalyst thereby enhancing the reaction progress. Nevertheless, Sinha and He et al. [44,118] also reported the high conversion of benzene over the V-Schiff-base functionalized mesoporous silica and bimetal V-Cu modified HMS, but the selectivity towards phenol was relatively low just with $60 \%$ and 29\%, respectively. Additionally, our group has also done much work on the direct oxidation of benzene by using the transition metal modified mesoporous silica. We employed the high content of $\mathrm{Cu}$ doping mesoporous MCM-41 [119], wherein the Cu-doped mesoporous MCM-41 afforded the superior catalytic conversion $(\sim 30 \%)$ for the benzene oxidation, and with the addition of promoters of $\mathrm{B}, \mathrm{Al}, \mathrm{Zr}$ or $\mathrm{Ti}$, the selectivity of phenol could be up to $100 \%$. Owing to the limitation of doping tactic for the mesoporous silica materials, our group [67] also developed the cationic surfactant induced dispersion strategy for the synthesis of highly-dispersed $\mathrm{VO}_{x}$ inside the mesopores of MCM-41; consequently, the catalytic active $\mathrm{VO}_{x}$ species exhibited the appreciable exposure and corresponding catalytic performance $\left(29.8 \%\right.$ conversion and $90 \%$ selectivity). Apart from those, the $\mathrm{O}_{2}$ oxidation of benzene was extended by Sun et al. [120]; through V/C modified silica-based mesoporous material and the conversion of benzene, selectivity of phenol was $12 \%$ and $100 \%$, respectively. The catalytic properties of different catalysts on benzene oxidation are shown in Table 1.

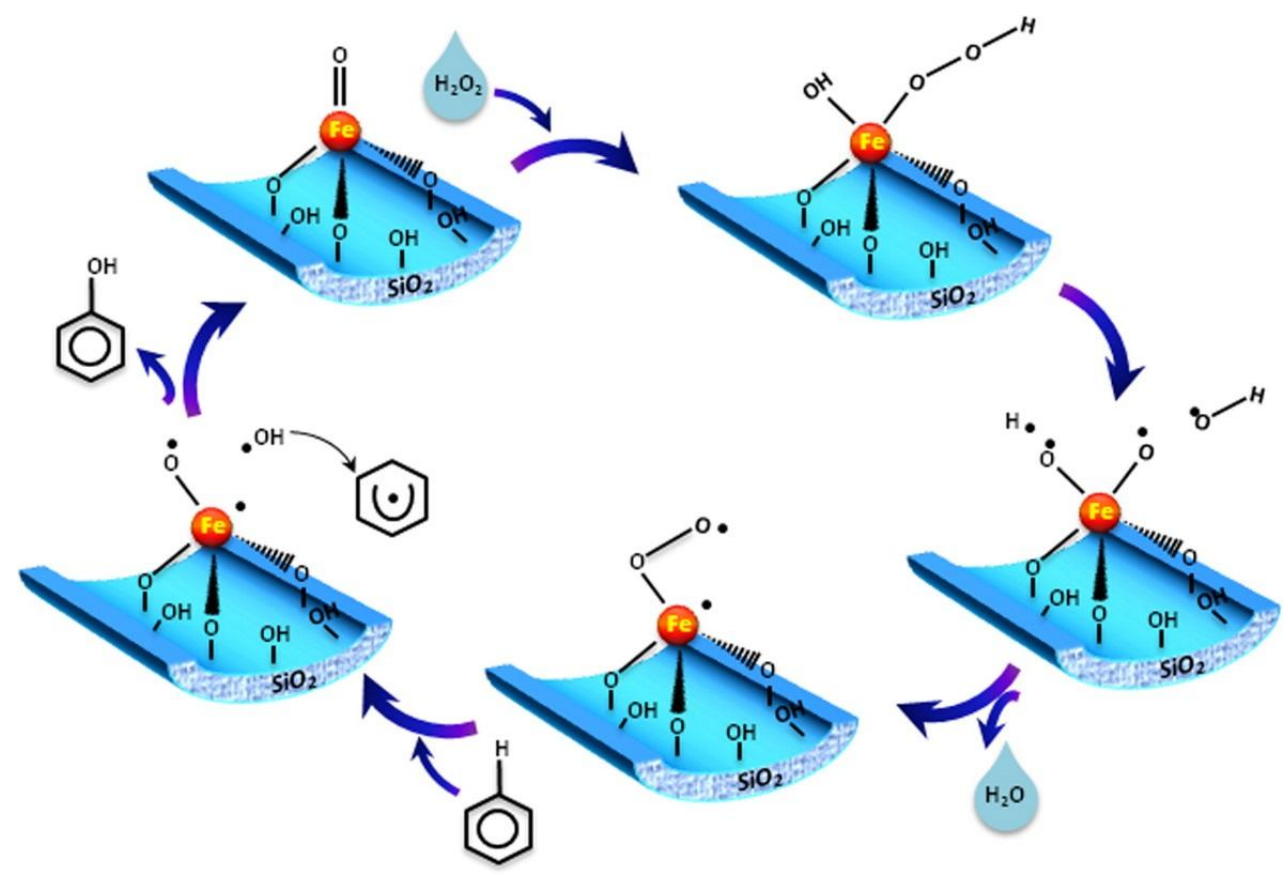

Figure 14. Mechanism of the Catalytic Benzene Hydroxylation by $\mathrm{H}_{2} \mathrm{O}_{2}$ in the Presence of Fe/SBA-16. Reprinted with permission from [116], Copyright 2016, American Chemical Society. 
Table 1. Catalytic properties of different catalysts on benzene oxidation.

\begin{tabular}{|c|c|c|c|c|c|c|c|}
\hline Catalyst & Oxidant & Solvent & Temperature ${ }^{\circ} \mathrm{C}$ & Time h & Conv. $\%$ & Phenol Sel. \% & Ref. \\
\hline $\mathrm{Fe} / \mathrm{SBA}-16$ & $\mathrm{H}_{2} \mathrm{O}_{2}$ & $\mathrm{CH}_{3} \mathrm{CN}$ & 65 & 8 & 12.1 & 96.4 & [116] \\
\hline V-Ti-MCM-41 & $\mathrm{H}_{2} \mathrm{O}_{2}$ & - & 30 & 5 & 22.3 & 94.7 & [121] \\
\hline V/DMDS- $x /$ SBA-15 & $\mathrm{H}_{2} \mathrm{O}_{2}$ & HAc & 70 & 3.5 & 34.1 & 93.2 & [117] \\
\hline $\mathrm{Cu}_{x}$-V-HMS & $\mathrm{H}_{2} \mathrm{O}_{2}$ & HAc & 70 & 3.5 & 31.5 & 29 & [44] \\
\hline V-Schiff base SBA-15 & $\mathrm{H}_{2} \mathrm{O}_{2}$ & $\mathrm{CH}_{3} \mathrm{CN}$ & 50 & 8 & 37.35 & 60 & [118] \\
\hline$\left[\mathrm{Cu}^{\mathrm{II}}(\mathrm{tmpa})\right]^{2+} @ \mathrm{Al}-\mathrm{MCM}-41$ & $\mathrm{H}_{2} \mathrm{O}_{2}$ & Acetone & 25 & 50 & 11.7 & $>99$ & [122] \\
\hline$\left[(\text { tpa }) \mathrm{Mn}^{\mathrm{II}}\right]^{2+} @ \mathrm{Al}-\mathrm{MCM}-41$ & $\mathrm{H}_{2} \mathrm{O}_{2}$ & $\mathrm{CH}_{3} \mathrm{CN}$ & 25 & 25 & 11 & 100 & [123] \\
\hline F-Ti-M-M & $\mathrm{H}_{2} \mathrm{O}_{2}$ & Butanone & 60 & 30 & 96.6 & $>99$ & [124] \\
\hline Co-SBA-16 & $\mathrm{H}_{2} \mathrm{O}_{2}$ & $\mathrm{CH}_{3} \mathrm{CN}$ & 70 & 4 & 28.8 & 96.6 & [43] \\
\hline Co-MCM-41 & $\mathrm{H}_{2} \mathrm{O}_{2}$ & HAc & 65 & 12 & 35.4 & 100 & [125] \\
\hline CuO-KIT-6 & $\mathrm{H}_{2} \mathrm{O}_{2}$ & $\mathrm{CH}_{3} \mathrm{CN}$ & 65 & 4 & 51 & 100 & [126] \\
\hline 20Cu-MCM-41 & $\mathrm{H}_{2} \mathrm{O}_{2}$ & $\mathrm{CH}_{3} \mathrm{CN}$ & 65 & 2.5 & 52.9 & 58.9 & [119] \\
\hline 1Cr20Cu-MCM-41 & $\mathrm{H}_{2} \mathrm{O}_{2}$ & $\mathrm{CH}_{3} \mathrm{CN}$ & 65 & 2.5 & 61.0 & 51.7 & [119] \\
\hline 1Al20Cu-MCM-41 & $\mathrm{H}_{2} \mathrm{O}_{2}$ & $\mathrm{CH}_{3} \mathrm{CN}$ & 65 & 2.5 & 33.0 & 100 & [119] \\
\hline $60 \mathrm{~V} / \mathrm{MCM}$ & $\mathrm{H}_{2} \mathrm{O}_{2}$ & $\mathrm{CH}_{3} \mathrm{CN}$ & 30 & 10 & 29.1 & 90 & [67] \\
\hline $\mathrm{C} / \mathrm{V}-\mathrm{SiO}_{2}$ & $\mathrm{O}_{2}$ & $\mathrm{CH}_{3} \mathrm{CN}$ & 90 & 10 & 12.0 & 100 & [120] \\
\hline V-SBA-15 & $\mathrm{O}_{2}$ & HAc & 140 & 15 & 4.6 & 61 & [127] \\
\hline
\end{tabular}

\subsection{Styrene Oxidation}

The oxidation of styrene using transition metal-based mesoporous silica has also attracted wide attention because of their excellent catalytic activity. Considerable endeavors have been devoted to the exploration of the enhancement of catalytic properties. Obviously, catalytic conversion of styrene over those catalysts is definitively affected by catalytic metal types especially for metal $\mathrm{Ni}, \mathrm{Ti}, \mathrm{Ce}, \mathrm{Co}$, $\mathrm{Mn}, \mathrm{Cu}$ and so on. For instance, Wongkasemjit et al. [128] reported that transition metal Ti modified SBA-15 affords $25.8 \%$ conversion and $34.2 \%$ selectivity to styrene oxide (SO) under a mild reaction condition. Fraile et al. [129] found that Ti/MCM- 41 gave $68 \%$ conversion and $44 \%$ selectivity to styrene oxide using TBHP as the oxidant under $70{ }^{\circ} \mathrm{C}$. Compared to other counterparts, it is noted that the catalytic conversion of styrene based on $\mathrm{Co}$ [130] and $\mathrm{Ni}$ [131] catalysts can be overtly enhanced to $93.9 \%$ and $95.2 \%$, respectively. However, these catalytic results present low selectivity towards styrene oxide, which seems to be undesirable. Therefore, further catalytic research using $\mathrm{Mn}$ or $\mathrm{Cu}$ based mesoporous silica has been conducted. Liu et al. [132] demonstrated Mn-modified MCM-41 affording $99.5 \%$ catalytic conversion and $90.2 \%$ selectivity to styrene oxide, extremely beyond most research results, and a possible reaction mechanism for the epoxidation of styrene on Mn-MCM-41 is shown in Figure 15. The catalytic properties of different catalysts on styrene oxidation are shown in Table 2. Besides, the cluster-like $\mathrm{CuO}$ dominant nearly-microporous AMS gives the ultra-high catalytic epoxidation activity for the various olefins and the catalytic activity is directly related with the pore size of the catalysts [72]. As illustrated in Figure 16, the CuO-based catalysts based on different kinds of support were prepared and used in the styrene epoxidation. Attributed to the different pore size of each catalyst, the diffused process of reactant molecules in the channels and their interactions with active sites would be different. The narrow channels prevent the fast diffusion process and promote the contact and collision frequency between reactant molecules and active sites. Thus, the micropore-enriched 3CuO-AMS catalyst with highly-dispersed cluster-like $\mathrm{CuO}$ displayed improved catalytic performance: $94.5 \%$ styrene conversion and $91.7 \%$ styrene oxide selectivity. 


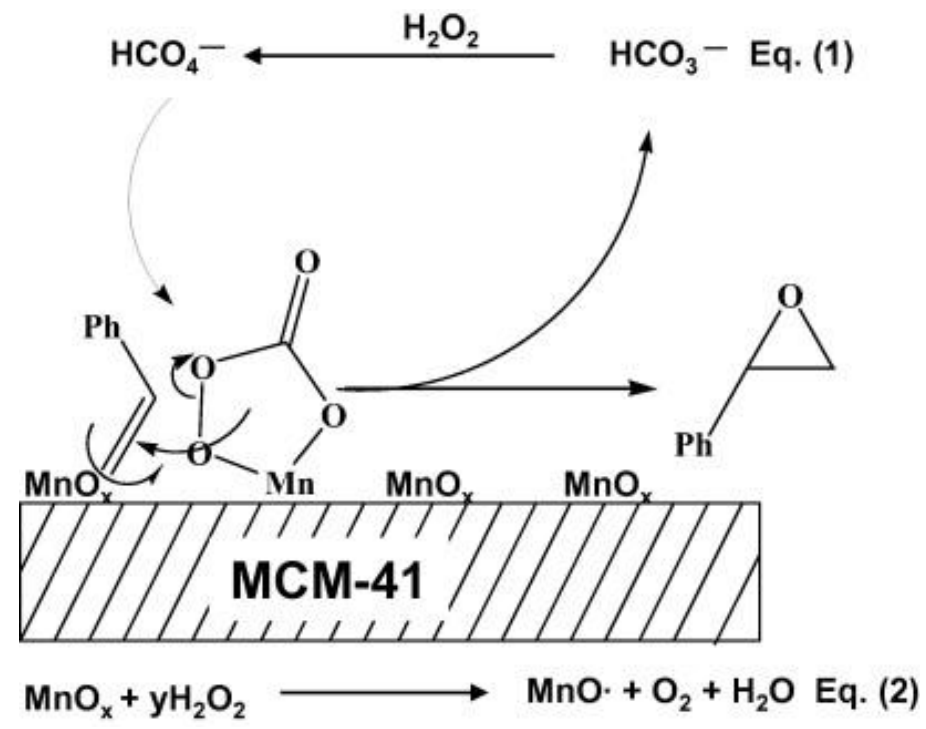

Figure 15. Possible reaction mechanism for the epoxidation of styrene on Mn-MCM-41. Reprinted from Ref. [132], Copyright 2014, with permission from Elsevier.

Table 2. Catalytic properties of different catalysts on styrene oxidation.

\begin{tabular}{cccccccc}
\hline Catalyst & Oxidant & Solvent & Temperature ${ }^{\circ} \mathbf{C}$ & Time $\mathbf{h}$ & Conv. $\%$ & SO Sel. $\%$ & Ref. \\
\hline $\mathrm{In}_{2} \mathrm{O}_{3} /$ TUD-1 & $\mathrm{O}_{2}$ & DMF & 130 & 8 & 25 & 60 & {$[133]$} \\
$\mathrm{Co} / \mathrm{SBA}-15$ & $\mathrm{O}_{2}$ & $\mathrm{DMF}$ & 100 & 6 & 93.9 & 65.5 & {$[130]$} \\
$\mathrm{MCM}-41-\mathrm{Ni}$ & $\mathrm{O}_{2}$ & $\mathrm{DMF}$ & 100 & 6 & 95.2 & 66.7 & {$[131]$} \\
$\mathrm{Cu}(\mathrm{II})-\mathrm{Co}_{3} \mathrm{O}_{4} / \mathrm{KIT}-6$ & $\mathrm{TBHP}$ & $\mathrm{DMF}$ & 70 & 24 & 100 & 45.2 & {$[134]$} \\
$\mathrm{Ti} / \mathrm{MCM}-41$ & $\mathrm{TBHP}$ & $\mathrm{DMF}$ & 70 & 24 & 68 & 44 & {$[129]$} \\
$\mathrm{Cu}-\mathrm{KIT}-6$ & $\mathrm{TBHP}$ & $\mathrm{CH}_{3} \mathrm{CN}$ & 70 & 6 & 43.5 & 86.6 & {$[135]$} \\
$\mathrm{CuO} / \mathrm{AMS}$ & $\mathrm{TBHP}$ & $\mathrm{CH}$ CN & 70 & 6 & 94.5 & 91.7 & {$[72]$} \\
$\mathrm{Ce}-\mathrm{Ti}-\mathrm{TUD}-1$ & $\mathrm{H}_{2} \mathrm{O}_{2}$ & $\mathrm{DMF}$ & 80 & 24 & 20.84 & 41.93 & {$[136]$} \\
Ti-MSSs & $\mathrm{H}_{2} \mathrm{O}_{2}$ & $\mathrm{DMF}$ & 60 & 6 & 44.7 & 17.7 & {$[137]$} \\
$\mathrm{Co}-\mathrm{SBA}-15$ & $\mathrm{H}_{2} \mathrm{O}_{2}$ & $\mathrm{DMF}$ & 70 & 10 & 34.7 & 88.2 & {$[138]$} \\
$\mathrm{Co}-\mathrm{MCM}-41$ & $\mathrm{H}_{2} \mathrm{O}_{2}$ & $\mathrm{DMF}$ & 70 & 10 & 27.0 & 84.0 & {$[138]$} \\
Ti-SBA-15 & $\mathrm{H}_{2} \mathrm{O}_{2}$ & DMF & 25 & 6 & 25.8 & 34.2 & {$[128]$} \\
Mn-MCM-41 & $\mathrm{H}_{2} \mathrm{O}_{2}$ & DMF & 25 & 1 & 99.5 & 90.2 & {$[132]$} \\
V/DMDS- $x$ /SBA-15 & $\mathrm{H}_{2} \mathrm{O}_{2}$ & DMF & 70 & 5 & 67.1 & 88.5 & {$[117]$} \\
\hline
\end{tabular}

(a)

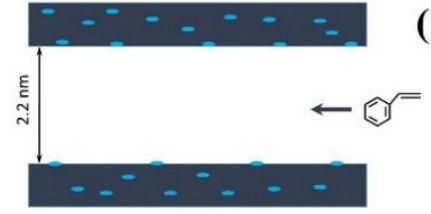

$3 \mathrm{Cu}-\mathrm{MCM}-41(\mathrm{~d})$

(d)

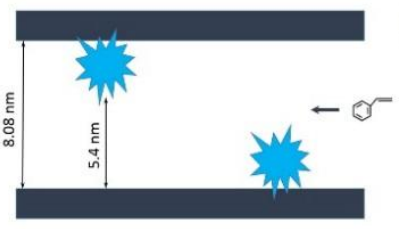

3CuO/SBA-15(p) (b)

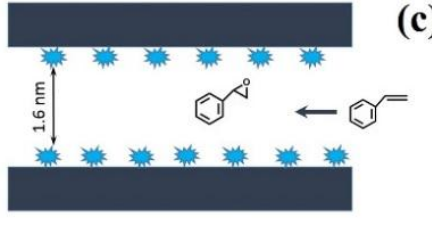

3CuO/AMS

(e)

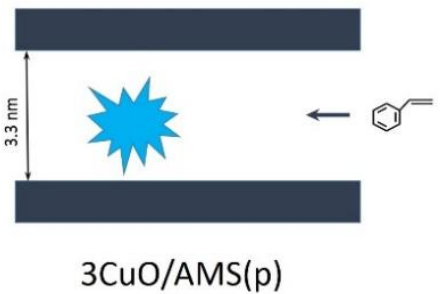

(c)

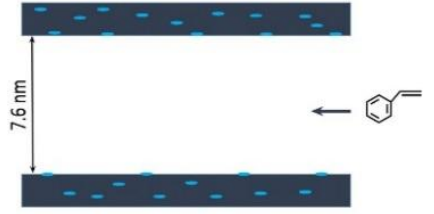

3Cu-SBA-15(d)

Figure 16. Depiction for the diffusion of styrene inside the pore channels of different catalysts in epoxidation process: (a) 3Cu-MCM-41(d), (b) 3CuO/AMS, (c) 3Cu-SBA-15(d), (d) 3CuO/SBA-15(p), (e) $3 \mathrm{CuO} / \mathrm{AMS}(\mathrm{p})$. 


\subsection{Ethylbenzene Oxidation}

In the case of the oxidation of ethylbenzene, various transition metal-based mesoporous silica exhibited appreciable catalytic activity and several products, including acetophenone (AP, main product), 1-phenylethanol (PE) and benzaldehyde (BP), have been involved. Especially, the transition metals of $\mathrm{Mn}, \mathrm{Co}$, and $\mathrm{Cu}$ have been used most widely. Liu et al. [139] synthesized Co-based $\mathrm{Co}-\mathrm{N}-\mathrm{C} / \mathrm{SiO}_{2}$ catalyst, which affords $12.9 \%$ conversion and $76.1 \%$ selectivity towards AP. Subsequently, Liu et al. [140] developed the Mn-based $\mathrm{Mn}-\mathrm{N}-\mathrm{C} / \mathrm{SiO}_{2}$ using Mn-porphyrin as the precursor with the enhancive catalytic conversion of $15.7 \%$ for ethylbenzene. The tert-Butyl hydroperoxide (TBHP) induced oxidation process has also been studied by Singh et al. [141] using the Co-HMS through the heterogenization of cobalt acetylacetonate; they demonstrated $49 \%$ conversion but with the sacrificed selectivity of $60 \%$ to AP. Jermy et al. [142] obtained $53.9 \%$ conversion and $81.3 \%$ selectivity to AP on the catalyst of highly ordered three-dimensional V-SBA- 16 and a plausible reaction mechanism is shown in Figure 17. To our delight, the big breakthrough towards the oxidation of ethylbenzene using a magnetism-responsive $\mathrm{Fe}_{3} \mathrm{O}_{4} @ \mathrm{SiO}_{2}-\mathrm{NH}_{2} @ \mathrm{CS}-\mathrm{Co}$ (II) has been reached by Zhai et al. [143]. An 82.5\% conversion with a relatively high selectivity of $80.4 \%$ to AP was observed in the $\mathrm{H}_{2} \mathrm{O}_{2}$ oxidation system. On the other hand, the Mn-based mesoporous silica has been improved using different types of mesoporous support such as MCM-48 [41], or TUD [144], where $33 \%$ and $40 \%$ conversion of ethylbenzene can be obtained, respectively. The further exploration of ethylbenzene oxidation using $\mathrm{Gr}$ and $\mathrm{Cu}$ supported mesoporous silica has made big progress: a Gr-MCM-41 catalyst gave a $66 \%$ conversion and 90\% selectivity to AP [145]. Surprisingly, Burri et al. [146] developed Cu-SBA-15 catalyst with $94 \%$ conversion and $99 \%$ selectivity towards AP under multiple reuse process, which gives extremely promising industry potential. The catalytic properties of different catalysts on ethylbenzene oxidation are shown in Table 3.

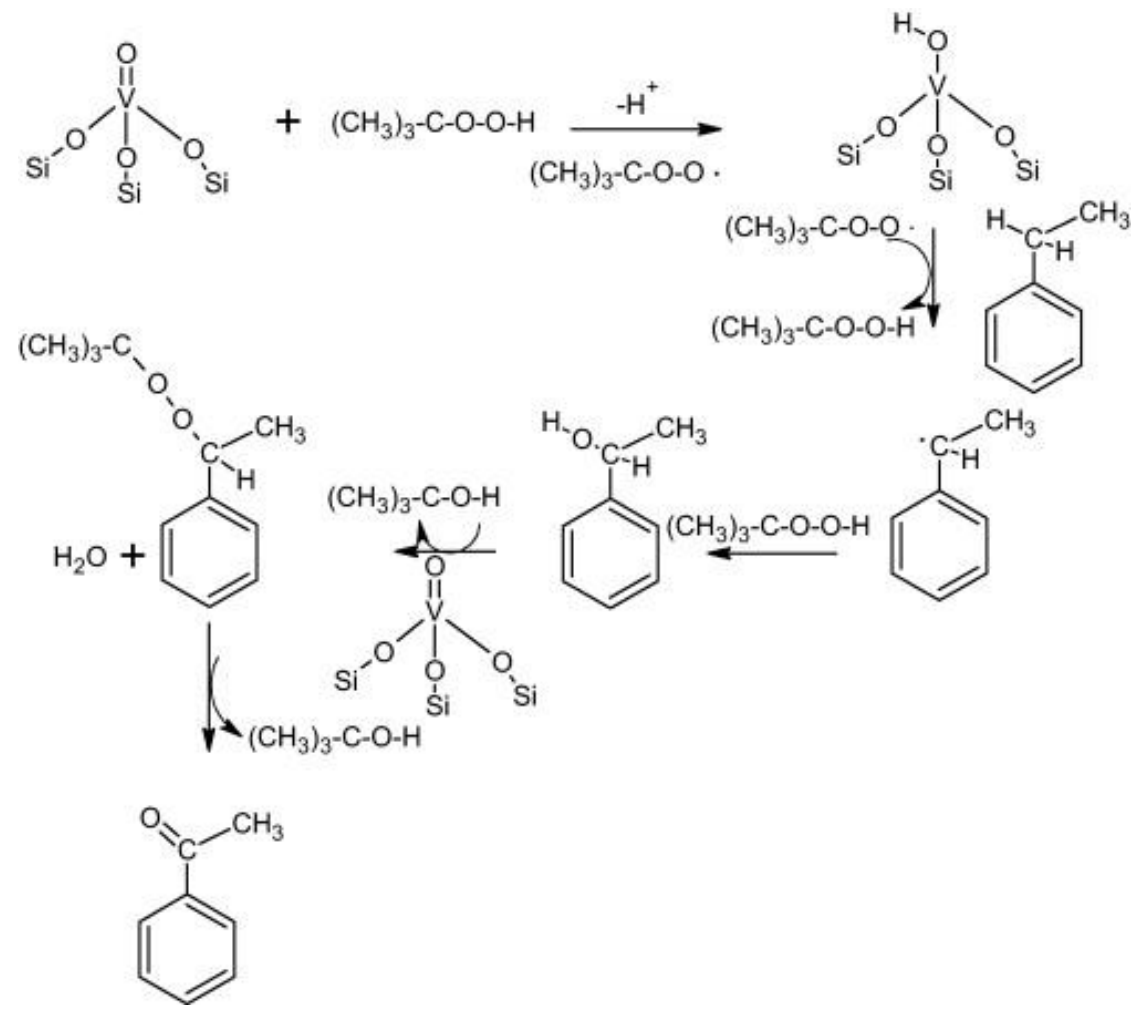

Figure 17. Plausible reaction mechanism for the selective oxidation of ethylbenzene to acetophenone over V-SBA-16 mesoporous molecular sieves. Reprinted from Ref. [142], Copyright 2011, with permission from Elsevier. 
Table 3. Catalytic properties of different catalysts on ethylbenzene oxidation.

\begin{tabular}{|c|c|c|c|c|c|c|c|c|c|}
\hline \multirow{2}{*}{ Catalyst } & \multirow{2}{*}{ Oxidant } & \multirow{2}{*}{ Solvent } & \multirow{2}{*}{ Temperature ${ }^{\circ} \mathrm{C}$} & \multirow{2}{*}{ Time h } & \multirow{2}{*}{ Conv. $\%$} & \multicolumn{3}{|c|}{ Sel. \% } & \multirow{2}{*}{ Ref. } \\
\hline & & & & & & AP & PE & BP & \\
\hline $\mathrm{MnO}_{x} / \mathrm{TS}-1$ & $\mathrm{O}_{2}$ & 1 & 150 & 1 & 37.1 & 68.6 & 20.4 & 3.4 & [147] \\
\hline $\mathrm{Mn}-\mathrm{N}-\mathrm{C} @ \mathrm{SiO}_{2}$ & $\mathrm{O}_{2}$ & 1 & 120 & 5 & 15.7 & 73.6 & 19 & 7.4 & [140] \\
\hline Co(III)(cyclam)py,-SBA-15 & $\mathrm{O}_{2}$ & 1 & RT & 5 & 30 & 70 & - & - & [148] \\
\hline $\mathrm{Co}-\mathrm{N}-\mathrm{C} / \mathrm{SiO}_{2}$ & $\mathrm{O}_{2}$ & 1 & 120 & 5 & 12.9 & 76.1 & 17.5 & 6.3 & [139] \\
\hline Co/SBA-15 & $\mathrm{O}_{2}$ & 1 & 120 & 9 & 70.1 & 83.7 & 4.1 & 0.1 & [149] \\
\hline MnMCM-41 & $\mathrm{O}_{2}$ & 1 & 110 & 6 & 34 & 88 & - & - & [41] \\
\hline CrMCM-41 & $\mathrm{O}_{2}$ & 1 & 95 & 24 & 66 & 90 & - & - & [145] \\
\hline SF-ATPS-Mn(III)TMCPP & ТВHР & - & 150 & 24 & 40.8 & 96.6 & 2.2 & 1.2 & [146] \\
\hline MnTUD-1 & TBHP & $\mathrm{CH}_{3} \mathrm{CN}$ & 80 & 8 & 19.8 & 60.8 & 26.6 & 12.6 & [144] \\
\hline Mn-MCM-41 & TBHР & $\mathrm{CH}_{3} \mathrm{CN}$ & 80 & 6 & 57.7 & 82.2 & - & 18 & [150] \\
\hline Mn-MCM-41 & TBHP & - & 80 & 24 & 66.1 & 43.8 & 40.8 & 5.1 & [151] \\
\hline Mn-Ti-MCM-41 & TBHP & $\mathrm{CH}_{3} \mathrm{CN}$ & 80 & 2 & 92 & 87 & 9 & 4 & [152] \\
\hline Co-HMS & TBHP & - & 80 & 24 & 49 & 60 & 25 & 15 & [141] \\
\hline CoTUD-1 & TBHP & $\mathrm{CH}_{3} \mathrm{CN}$ & 80 & 8 & 38 & 74 & 17 & 9 & [153] \\
\hline V-SBA-16 & TBHP & $\mathrm{CH}_{3} \mathrm{CN}$ & 80 & 24 & 53.9 & 81.3 & 18.5 & - & [142] \\
\hline MCM-41-L/CuCl 2 & TBHP & $\mathrm{CH}_{3} \mathrm{CN}$ & 30 & 24 & 45 & 98 & - & - & [154] \\
\hline $\mathrm{Fe}_{3} \mathrm{O}_{4} @ \mathrm{SiO}_{2}-\mathrm{NH}_{2} @ \mathrm{CS}-\mathrm{Co}(\mathrm{II})$ & $\mathrm{H}_{2} \mathrm{O}_{2}$ & HOAc & 70 & 1 & 82.5 & 80.4 & - & - & [143] \\
\hline
\end{tabular}

\subsection{Other Oxidation of Aromatic Derivatives}

Additionally, transition metal-based mesoporous silicas have also been widely applied in other aromatic derivatives oxidation, such as phenol, methylbenzene, benzyl alcohol, naphthalene, etc., because of their similar mild reaction conditions. Especially, the phenol oxidation towards dihydroxybenzene shows considerable attraction. Based on plenty of research, the transition metals Sn $[155,156]$, $\mathrm{Cu}[157,158], \mathrm{Mn}[159], \mathrm{Fe}$ [42,71,160,161], Co [74,162], etc. exhibit efficient catalytic conversion for phenol oxidation. Iron atom emerging as the active species affords the special catalytic conversion in the aqueous reaction system, and Fe-based mesoporous silica is thereby regarded as a promising catalyst in the phenol oxidation. Besides, the morphology and structure of the catalysts would directly influence the catalytic performance. Based on our previous reports [107], through controlling the length from $150 \mathrm{~nm}$ to $1.2 \mu \mathrm{m}$, the Fe-based mesoporous silica nanotubes (Fe-NTRs) show the adjustable catalytic property corresponding to different diffusing rates. Owing to the hydrophilic inner surface of Fe-NTRs by the presence of abundant silanol groups, the adsorption of solvent water is competitive with the reactant molecules of phenol on the active sites. In this case, the longer length of nanotubes effectively increases the inner diffusion time of reactors (Figure 18). Therefore, by increase the length of Fe-NTRs, the adsorption of phenol on the active sites was improved, and the conversion rate of phenol was accordingly promoted (Table 4). However, it is worth noting that the single-metal iron modified mesoporous silica tends to give the low selectivity of dihydroxybenzene thanks to the superior oxidation capacities of $\mathrm{Fe} / \mathrm{H}_{2} \mathrm{O}_{2}$ Fenton system [105]. Therefore, many studies have developed the promoted metal catalysts doping tactic to improve the catalytic selectivity of dihydroxybenzene $[83,163,164]$. Metal promoters such as $\mathrm{Mn}$ and $\mathrm{Al}$ can efficiently enhance the dihydroxybenzene selectivity during the reaction process. Apart from these, our group directly incorporated $\mathrm{Fe}_{2} \mathrm{O}_{3}$ clusters inside the mesoporous AMS [71], and the encapsulation of $\mathrm{FeO}_{x}$ resulted in the formation of enriched micropores in the Fe/AMS catalysts. As shown in Table 5, due to shape selective of the microporous materials of TS-1 (Titanium Silicalite-1) and ZSM-5, the relatively large molecules of by-products could be hardly produced in the microporous channels, leading to extremely high selectivity of dihydroxybenzene. However, compared with AMS-series materials, the low surface area of TS- 1 and ZSM- 5 leads to decreased number of exposed active sites, making low catalytic activity. Based on these, attributed to the enriched micropores and high surface area, the Fe/AMS catalysts display high catalytic conversion and certain selectivity to dihydroxybenzene for the phenol hydroxylation. 


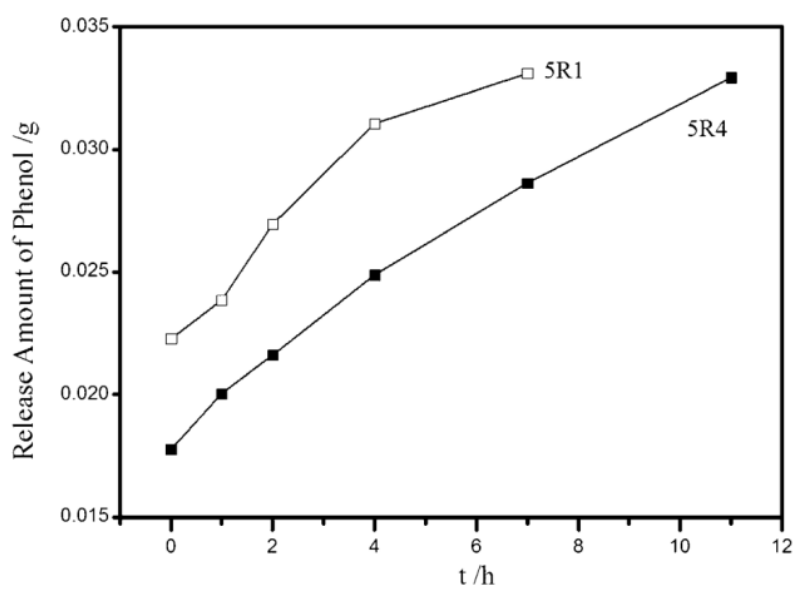

Figure 18. Release profiles of typical $5 \mathrm{R} 1$ and 5 R4 with different lengths. Reproduced with permission from [107]. Copyright 2015, John Wiley and Sons.

Table 4. Catalytic activity of Fe-NTRs with different length. Reproduced with permission from [107]. Copyright (2015) John Wiley and Sons.

\begin{tabular}{ccccccc}
\hline Samples & Length $(\boldsymbol{\mu m})$ & Iron Content $^{\mathbf{a}} \mathbf{( w t .} \mathbf{\% )}$ & $\mathbf{X}^{\mathbf{b}} \mathbf{( \% )}$ & $\mathbf{S}^{\mathbf{c}} \mathbf{( \% )}$ & $\mathbf{Y}^{\mathbf{d}} \mathbf{( \% )}$ & Cat./Hyd. $^{\mathbf{e}}$ \\
\hline 5 R1 & 0.15 & 0.68 & 35.5 & 61.8 & 21.9 & 1.55 \\
5 R3 & 0.60 & 0.65 & 48.8 & 55.6 & 27.1 & 1.49 \\
5 R4 & 0.80 & 0.65 & 50.1 & 50.5 & 25.3 & 1.48 \\
5 R5 & 1.20 & 0.65 & 40.6 & 47.2 & 19.2 & 1.42 \\
\hline
\end{tabular}

${ }^{\mathrm{a}}$ ICP results; ${ }^{\mathrm{b}}$ Phenol conversion; ${ }^{\mathrm{c}}$ Dihydroxybenzene selectivity; ${ }^{\mathrm{d}}$ Yield; ${ }^{\mathrm{e}}$ Molar ratio of catechol/hydroquinone.

Table 5. The catalytic activities of the samples with different pore size for phenol hydroxylation.

\begin{tabular}{|c|c|c|c|c|c|c|}
\hline Samples a & $\begin{array}{c}\text { Pore Size } \\
\text { (nm) }\end{array}$ & $\begin{array}{l}\mathrm{Fe} / \mathrm{Si}^{\mathrm{c}} \\
\text { (wt. \%) }\end{array}$ & $\begin{array}{l}\text { Fe/Si d } \\
\text { (wt. \%) }\end{array}$ & $\begin{array}{c}X(P h) \\
(\%)\end{array}$ & $\begin{array}{c}\text { S(CAT) } \\
(\%)\end{array}$ & $\begin{array}{c}S(H Q) g \\
(\%)\end{array}$ \\
\hline $0.05 \mathrm{Fe} / \mathrm{AMS}$ & 1.72 & 1.11 & 0.92 & 29.8 & 44.3 & 28.4 \\
\hline $0.1 \mathrm{Fe} / \mathrm{AMS}$ & 1.72 & 2.23 & 1.62 & 34.8 & 49.4 & 29.7 \\
\hline $0.15 \mathrm{Fe} / \mathrm{AMS}$ & 1.72 & 3.50 & 2.53 & 44.3 & 52.2 & 30.4 \\
\hline $0.20 \mathrm{Fe} / \mathrm{AMS}$ & 1.67 & 4.67 & 2.89 & 43.6 & 50.1 & 30.3 \\
\hline $0.15 \mathrm{Fe} / \mathrm{MCM}-41(\mathrm{p})^{h}$ & 2.40 & 3.50 & 2.52 & 38.6 & 32.8 & 18.6 \\
\hline $0.15 \mathrm{Fe} / \mathrm{SBA}-15(\mathrm{p})$ & 5.40 & 3.50 & 2.61 & 40.1 & 26.1 & 19.4 \\
\hline $0.15 \mathrm{Fe} / \mathrm{AMS}(\mathrm{p})$ & 2.60 & 3.50 & 2.50 & 36.7 & 31.4 & 19.6 \\
\hline TS-1 & 0.54 & - & - & 29 & 50.2 & 49.8 \\
\hline Fe-ZSM-5 & 0.50 & 2.00 & 1.54 & 32.9 & 60.5 & 39.5 \\
\hline
\end{tabular}

${ }^{a}$ Reaction conditions: molar ratio, phenol $/ \mathrm{H}_{2} \mathrm{O}_{2}=2: 1$, time, $2 \mathrm{~h}$, reaction temperature, room temperature; ${ }^{\mathrm{b}}$ It is calculated by BJH method using desorption data; ${ }^{c}$ The initial Fe/Si mass ratios in the synthesis gel; ${ }^{d}$ Fe/Si mass ratios are determined by ICP-AES (Inductively Coupled Plasma-Atomic Emission Spectrometry); ${ }^{\mathrm{e}}$ The conversion of phenol; ${ }^{\mathrm{f}}$ The selectivity of catechol; $\mathrm{g}$ The selectivity of hydroquinone; ${ }^{\mathrm{h}}$ The post synthesized sample.

The oxidation of methylbenzene based on the transition metal-based mesoporous silica catalyst has afforded some considerable catalytic results. It is worth noting that the selective oxidation of methylbenzene towards benzyl alcohol, benzaldehyde and benzoic acid gives industry the possibility of utilizing methylbenzene towards value-added chemicals. For instance, Mao et al. [165] demonstrated the Mn-based SBA-15 can efficiently catalyze methylbenzene to benzoic acid with the $24.7 \%$ conversion and 79.5\% selectivity. Mou et al. [166] used tripodal tridentate copper complex containing mesoporous silica to efficiently activate the methylbenzene aliphatic $\mathrm{C}-\mathrm{H}$ bond and synthesize the benzyl alcohol, and benzaldehyde. Moreover, the total oxidation removal of methylbenzene could be obtained over the various metals modified mesoporous silica such as Co-MCM-41 [167], Cu-MCM-41/SBA-15 [168,169], 
Mn-SBA-15 [170], Fe-Ti-MCM-41 [171], Cu-Mn-MCM-14 [169], etc. Furthermore, the further oxidation of benzyl alcohol has also been noticed using the transition metal-based mesoporous silica. For example, Casuscelli et al. [172] reported V-, Fe-, and Co-MCM-41 for the oxidation of benzyl alcohol, but only the Fe-based MCM-41 gives relatively remarkable catalytic activity of $13.3 \%$ conversion and $90.5 \%$ selectivity towards benzaldehyde (BP). Afterwards, Cai et al. [173] developed the ion liquid- $\mathrm{FeCl}_{3}$ mesoporous silica, and an enhancive catalytic activity has been reached that conversion of $61.8 \%$ and selectivity of $73.6 \%$ to BP. Interestingly, the Co-Schiff-based heterogenized mesoporous silica has been demonstrated by Sinha et al. [174] and affords $98 \%$ yield of BP.

\section{Summary and Outlook}

During the past few decades, introduction of different kinds of acidic/basic and redox metal active sites into the specific locations of OMSs, including mesoporous channels and framework, with the assistant of the organic groups and the applications of metal-functionalized OMSs in the oxidation of aromatic compounds have obtained great achievements. The direct synthesis pathways of metal-functionalized OMSs have been reported, and the influence of morphology and channel structure of OMSs on the external and internal diffusion has been outlined. The transition metal functionalized OMSs showed good catalytic activity in various kinds of the oxidation of aromatic compounds.

However, there are still several challenges for the future studies and practical applications of metal-functionalized OMSs. Firstly, the decoration of active metals in the specific locations by the direct synthesis routes with the help of organic groups would open a new vision in the creating of metal-functionalized OMSs. Although the strong interactions between active metals and support were obtained in OMSs with the help of organic groups, the controllable morphology and structure of OMSs synthesized by these direct synthesis routes have not been well developed. Secondly, some efforts have been put forward on the controllable morphology and structure of the metal-functionalized OMSs catalysts, but the mechanistic aspects of these process have not been completely understood. Obviously, in this review, the morphology, particle size, and size and length of the pore channels of OMSs materials significantly influence the reaction process on OMSs catalysts. It is still difficult to understand the relationship of the structural morphology of OMSs to the electronic structure of active species, thus the development of advanced characterization techniques is needed. Finally, the oxidation of aromatic compounds through the transition metal modified OMSs are extremely promising thanks for the ideal mesoporous carrier. However, the decoration of multiple metal active species and their synergistic interactions on the surface of mesoporous silica remain to be explored in the future.

Acknowledgments: We are grateful to National Natural Science Foundation of China (Nos. 21476108, 21276125, 21776129, and 21706121), Natural Science Foundations of Jiangsu Province (No. BK20170995), General Program for University Natural Science Research of Jiangsu Province (No. 16KJB530003) and the Project of Priority Academic Program Development of Jiangsu Higher Education Institutions (PAPD).

Author Contributions: S.Z., F.Y. and Y.K. designed the review structure, all authors contributed to write the paper, S.Z. and Y.K. iteratively brought it to its final state.

Conflicts of Interest: The authors declare no conflict of interest.

\section{References}

1. Sanz-Pérez, E.S.; Arencibia, A.; Calleja, G.; Sanz, R. Tuning the textural properties of HMS mesoporous silica. Functionalization towards $\mathrm{CO}_{2}$ adsorption. Microporous Mesoporous Mater. 2018, 260, 235-244. [CrossRef]

2. Dündar-Tekkaya, E.; Yürüm, Y. Mesoporous MCM-41 material for hydrogen storage: A short review. Int. J. Hydrogen Energy 2016, 41, 9789-9795. [CrossRef]

3. Chen, Z.; Luck, R.L. Oxidation of olefins using atmospheric oxygen atoms initiated by tert-butylhydroperoxide or hydrogen peroxide with silver nanoparticles deposited on MCM-41 as catalysts. Green Chem. 2016, 18, 3354-3359. [CrossRef]

4. Rosenholm, J.M.; Zhang, J.; Linden, M.; Sahlgren, C. Mesoporous silica nanoparticles in tissue engineering-A perspective. Nanomedicine 2016, 11, 391-402. [CrossRef] [PubMed] 
5. Tomer, V.K.; Duhan, S.; Adhyapak, P.V.; Mulla, I.S. Mn-loaded mesoporous silica nanocomposite: A highly efficient humidity sensor. J. Am. Ceram. Soc. 2015, 98, 741-747. [CrossRef]

6. Zhang, J.-H.; Xie, S.-M.; Zhang, M.; Zi, M.; He, P.-G.; Yuan, L.-M. Novel inorganic mesoporous material with chiral nematic structure derived from nanocrystalline cellulose for high-resolution gas chromatographic separations. Anal. Chem. 2014, 86, 9595-9602. [CrossRef] [PubMed]

7. Sarvi, M.N.; Budianto Bee, T.; Gooi, C.K.; Woonton, B.W.; Gee, M.L.; O'Connor, A.J. Development of functionalized mesoporous silica for adsorption and separation of dairy proteins. Chem. Eng. J. 2014, 235, 244-251. [CrossRef]

8. Newton, M.A.; Belver-Coldeira, C.; Martínez-Arias, A.; Fernández-García, M. Dynamic in situ observation of rapid size and shape change of supported Pd nanoparticles during Co/No cycling. Nat. Mater. 2007, 6, 528-532. [CrossRef] [PubMed]

9. Xin, H.L.; Mundy, J.A.; Liu, Z.; Cabezas, R.; Hovden, R.; Kourkoutis, L.F.; Zhang, J.; Subramanian, N.P.; Makharia, R.; Wagner, F.T; et al. Atomic-resolution spectroscopic imaging of ensembles of nanocatalyst particles across the life of a fuel cell. Nano Lett. 2012, 12, 490-497. [CrossRef] [PubMed]

10. Wynblatt, P.; Gjostein, N.A. Supported metal crystallites. Prog. Solid State Chem. 1975, 9, 21-58. [CrossRef]

11. Campbell, C.T.; Parker, S.C.; Starr, D.E. The effect of size-dependent nanoparticle energetics on catalyst sintering. Science 2002, 298, 811-814. [CrossRef] [PubMed]

12. Cao, A.; Veser, G. Exceptional high-temperature stability through distillation-like self-stabilization in bimetallic nanoparticles. Nat. Mater. 2009, 9, 75-81. [CrossRef] [PubMed]

13. Farmer, J.A.; Campbell, C.T. Ceria maintains smaller metal catalyst particles by strong metal-support bonding. Science 2010, 329, 933-936. [CrossRef] [PubMed]

14. Cheng, T.; Zhao, Q.; Zhang, D.; Liu, G. Transition-metal-functionalized ordered mesoporous silicas: An overview of sustainable chiral catalysts for enantioselective transformations. Green Chem. 2015, 17, 2100-2122. [CrossRef]

15. Heitbaum, M.; Glorius, F.; Escher, I. Asymmetric heterogeneous catalysis. Angew. Chem. Int. Ed. 2006, 45, 4732-4762. [CrossRef] [PubMed]

16. Taguchi, A.; Schüth, F. Ordered mesoporous materials in catalysis. Microporous Mesoporous Mater. 2005, 77, 1-45. [CrossRef]

17. Vinu, A.; Hossain, K.Z.; Ariga, K. Recent advances in functionalization of mesoporous silica. J. Nanosci. Nanotechnol. 2005, 5, 347-371. [CrossRef] [PubMed]

18. Rahman, S.; Shah, S.; Santra, C.; Sen, D.; Sharma, S.; Pandey, J.K.; Mazumder, S.; Chowdhury, B. Controllable synthesis of niobium doped mesoporous silica materials with various morphologies and its activity for oxidative catalysis. Microporous Mesoporous Mater. 2016, 226, 169-178. [CrossRef]

19. Xin, H.; Zhao, J.; Li, X.; Tang, J.; Yang, Q. An acid-free route for the facile synthesis of iron-functionalized mesoporous silicas: Transformation between hollow nanospheres and cage-like mesostructures. Microporous Mesoporous Mater. 2014, 190, 54-62. [CrossRef]

20. Wan, Y.; Shi, Y.; Zhao, D. Designed synthesis of mesoporous solids via nonionic-surfactant-templating approach. Chem. Commun. 2007, 897-926. [CrossRef] [PubMed]

21. Sayari, A.; Hamoudi, S. Periodic mesoporous silica-based organic-inorganic nanocomposite materials. Chem. Mater. 2001, 13, 3151-3168. [CrossRef]

22. Vu, X.; Armbruster, U.; Martin, A. Micro/mesoporous zeolitic composites: Recent developments in synthesis and catalytic applications. Catalysts 2016, 6, 183. [CrossRef]

23. Wang, H.; Li, X.; Wang, Y.M.; Wu, P. Pt nanoparticles supported on highly dispersed alumina coated inside SBA-15 for enantioselective hydrogenation. ChemCatChem 2010, 2, 1303-1311. [CrossRef]

24. Jiménez-Morales, I.; Moreno-Recio, M.; Santamaría-González, J.; Maireles-Torres, P.; Jiménez-López, A. Production of 5-hydroxymethylfurfural from glucose using aluminium doped MCM-41 silica as acid catalyst. Appl. Catal. B Environ. 2015, 164, 70-76. [CrossRef]

25. Zepeda, T.A.; Infantes-Molina, A.; de Leon, J.N.D.; Obeso-Estrella, R.; Fuentes, S.; Alonso-Nuñez, G.; Pawelec, B. Synthesis and characterization of Ga-modified Ti-HMS oxide materials with varying Ga content. J. Mol. Catal. A Chem. 2015, 397, 26-35. [CrossRef]

26. Chen, S.-Y.; Mochizuki, T.; Abe, Y.; Toba, M.; Yoshimura, Y. Ti-incorporated SBA-15 mesoporous silica as an efficient and robust lewis solid acid catalyst for the production of high-quality biodiesel fuels. Appl. Catal. B Environ. 2014, 148-149, 344-356. [CrossRef] 
27. Aziz, M.A.A.; Puad, K.; Triwahyono, S.; Jalil, A.A.; Khayoon, M.S.; Atabani, A.E.; Ramli, Z.; Majid, Z.A.; Prasetyoko, D.; Hartanto, D. Transesterification of croton megalocarpus oil to biodiesel over $\mathrm{WO}_{3}$ supported on silica mesoporous-macroparticles catalyst. Chem. Eng. J. 2017, 316, 882-892. [CrossRef]

28. Zakharova, M.V.; Kleitz, F.; Fontaine, F.-G. Lewis acidity quantification and catalytic activity of Ti, Zr and Al-supported mesoporous silica. Dalton Trans. 2017, 46, 3864-3876. [CrossRef] [PubMed]

29. Zhao, Y.; Zhang, X.; Song, X.; Liu, F. Highly active and recyclable mesoporous molecular sieves $\mathrm{CaO}(\mathrm{SrO}, \mathrm{BaO}) / \mathrm{SBA}-15$ with base sites as heterogeneous catalysts for methanolysis of polycarbonate. Catal. Lett. 2017, 147, 2940-2949. [CrossRef]

30. Jiang, L.; Diao, Y.; Han, J.; Yan, R.; Zhang, X.; Zhang, S. MgO-SBA-15 supported Pd-Pb catalysts for oxidative esterification of methacrolein with methanol to methyl methacrylate. Chin. J. Chem. Eng. 2014, 22, 1098-1104. [CrossRef]

31. Wang, N.; Yu, X.; Shen, K.; Chu, W.; Qian, W. Synthesis, characterization and catalytic performance of $\mathrm{MgO}-$ coated $\mathrm{Ni} / \mathrm{SBA}-15$ catalysts for methane dry reforming to syngas and hydrogen. Int. J. Hydrogen Energy 2013, 38, 9718-9731. [CrossRef]

32. Tantirungrotechai, J.; Thananupappaisal, P.; Yoosuk, B.; Viriya-Empikul, N.; Faungnawakij, K. One-pot synthesis of calcium-incorporated MCM-41 as a solid base catalyst for transesterification of palm olein. Catal. Commun. 2011, 16, 25-29. [CrossRef]

33. Sun, H.; Han, J.; Ding, Y.; Li, W.; Duan, J.; Chen, P.; Lou, H.; Zheng, X. One-pot synthesized mesoporous Ca/SBA-15 solid base for transesterification of sunflower oil with methanol. Appl. Catal. A Gen. 2010, 390, 26-34. [CrossRef]

34. Wu, Z.Y.; Jiang, Q.; Wang, Y.M.; Wang, H.J.; Sun, L.B.; Shi, L.Y.; Xu, J.H.; Wang, Y.; Chun, Y.; Zhu, J.H. Generating superbasic sites on mesoporous silica SBA-15. Chem. Mater. 2006, 18, 4600-4608. [CrossRef]

35. Michalska, A.; Daturi, M.; Saussey, J.; Nowak, I.; Ziolek, M. The role of MCM-41 composition in the creation of basicity by alkali metal impregnation. Microporous Mesoporous Mater. 2006, 90, 362-369. [CrossRef]

36. Thitsartarn, W.; Maneerung, T.; Kawi, S. Highly active and durable Ca-doped Ce-SBA-15 catalyst for biodiesel production. Energy 2015, 89, 946-956. [CrossRef]

37. Cano, L.A.; Cagnoli, M.V.; Bengoa, J.F.; Garcia-Fierro, J.L.; Marchetti, S.G. Synthesis and characterization of SBA-15 modified with alkali metals. J. Porous Mater. 2017, 24, 631-638. [CrossRef]

38. Lee, G.V.d.; Ponec, V. On some problems of selectivity in syngas reactions on the group VIII metals. Catal. Rev. 1987, 29, 183-218. [CrossRef]

39. Ngantsoue-Hoc, W.; Zhang, Y.; O’Brien, R.J.; Luo, M.; Davis, B.H. Fischer-tropsch synthesis: Activity and selectivity for group I alkali promoted iron-based catalysts. Appl. Catal. A Gen. 2002, 236, 77-89. [CrossRef]

40. Zhang, H.; Li, M.; Xiao, P.; Liu, D.; Zou, C.J. Structure and catalytic performance of Mg-SBA-15-supported nickel catalysts for $\mathrm{CO}_{2}$ reforming of methane to syngas. Chem. Eng. Technol. 2013, 36, 1701-1707.

41. Novak Tušar, N.; Laha, S.C.; Cecowski, S.; Arčon, I.; Kaučič, V.; Gläser, R. Mn-containing porous silicates as catalysts for the solvent-free selective oxidation of alkyl aromatics to aromatic ketones with molecular oxygen. Microporous Mesoporous Mater. 2011, 146, 166-171. [CrossRef]

42. Liang, X.; Yang, R.; Li, G.; Hu, C. Phenol hydroxylation over Fe-incorporated mesoporous materials prepared by coprecipitation. Microporous Mesoporous Mater. 2013, 182, 62-72. [CrossRef]

43. Dong, Y.; Zhan, X.; Niu, X.; Li, J.; Yuan, F.; Zhu, Y.; Fu, H. Facile synthesis of Co-SBA-16 mesoporous molecular sieves with EISA method and their applications for hydroxylation of benzene. Microporous Mesoporous Mater. 2014, 185, 97-106. [CrossRef]

44. Hu, L.; Yue, B.; Chen, X.; He, H. Direct hydroxylation of benzene to phenol on Cu-V bimetal modified HMS catalysts. Catal. Commun. 2014, 43, 179-183. [CrossRef]

45. Shen, S.; Chen, J.; Koodali, R.T.; Hu, Y.; Xiao, Q.; Zhou, J.; Wang, X.; Guo, L. Activation of MCM-41 mesoporous silica by transition-metal incorporation for photocatalytic hydrogen production. Appl. Catal. B Environ. 2014, 150-151, 138-146. [CrossRef]

46. Li, X.; Kong, Y.; Zhou, S.; Wang, B. In situ incorporation of well-dispersed Cu-Fe oxides in the mesochannels of AMS and their utilization as catalysts towards the fenton-like degradation of methylene blue. J. Mater. Sci. 2017, 52, 1432-1445. [CrossRef]

47. Corma, A. From microporous to mesoporous molecular sieve materials and their use in catalysis. Chem. Rev. 1997, 97, 2373-2420. [CrossRef] [PubMed]

48. Davis, M.E. Ordered porous materials for emerging applications. Nature 2002, 417, 813. [CrossRef] [PubMed] 
49. Qian, W.; Wang, H.; Chen, J.; Kong, Y. Spherical V-Fe-MCM-48: The synthesis, characterization and hydrothermal stability. Materials 2015, 8, 1752-1765. [CrossRef] [PubMed]

50. Zhou, J.; Scott, M.J.; Hu, Z.; Peng, G.; Munck, E.; Holm, R.H. Synthesis and comparative reactivity and electronic structural features of $\left[\mathrm{MFe}_{3} \mathrm{~S}_{4}\right]^{\mathrm{z}}$ cubane-type clusters $(\mathrm{M}=$ iron, cobalt, nickel). J. Am. Chem. Soc. 1992, 114, 10843-10854. [CrossRef]

51. Niu, K.; Liang, L.; Geng, H.; Hou, W.; Tian, H.; Liu, S. Chelating template-assisted fabrication of cobalt oxide/mesoporous silica composites with diverse mesophases. Mater. Lett. 2013, 107, 325-328. [CrossRef]

52. Niu, K.; Liang, L.; Gu, Y.; Ke, L.; Duan, F.; Chen, M. Fabrication and photoluminescent properties of $\mathrm{ZnO} /$ mesoporous silica composites templated by a chelating surfactant. Langmuir 2011, 27, 13820-13827. [CrossRef] [PubMed]

53. Niu, K.; Shi, D.; Dong, W.; Chen, M.; Ni, Z. Chelating template-induced encapsulation of NiO cluster in mesoporous silica via anionic surfactant-templated route. J. Colloid Interface Sci. 2011, 362, 74-80. [CrossRef] [PubMed]

54. Fang, J.; Li, J.; Zhang, B.; Yuan, X.; Asakura, H.; Tanaka, T.; Teramura, K.; Xie, J.; Yan, N. The support effect on the size and catalytic activity of thiolated $\mathrm{Au}_{25}$ nanoclusters as precatalysts. Nanoscale 2015, 7, 6325-6333. [CrossRef] [PubMed]

55. Da'na, E. Adsorption of heavy metals on functionalized-mesoporous silica: A review. Microporous Mesoporous Mater. 2017, 247, 145-157. [CrossRef]

56. Lim, W.Q.; Phua, S.Z.F.; Xu, H.V.; Sreejith, S.; Zhao, Y. Recent advances in multifunctional silica-based hybrid nanocarriers for bioimaging and cancer therapy. Nanoscale 2016, 8, 12510-12519. [CrossRef] [PubMed]

57. Albela, B.; Bonneviot, L. Surface molecular engineering in the confined space of templated porous silica. New J. Chem. 2016, 40, 4115-4131. [CrossRef]

58. Iliade, P.; Miletto, I.; Coluccia, S.; Berlier, G. Functionalization of mesoporous MCM-41 with aminopropyl groups by co-condensation and grafting: A physico-chemical characterization. Res. Chem. Intermed. 2012, 38, 785-794. [CrossRef]

59. Ursachi, I.; Stancu, A.; Vasile, A. Magnetic $\alpha-\mathrm{Fe}_{2} \mathrm{O}_{3} / \mathrm{MCM}-41$ nanocomposites: Preparation, characterization, and catalytic activity for methylene blue degradation. J. Colloid Interface Sci. 2012, 377, 184-190. [CrossRef] [PubMed]

60. Zhang, X.; Huang, N.; Wang, G.; Dong, W.; Yang, M.; Luan, Y.; Shi, Z. Synthesis of highly loaded and well dispersed $\mathrm{CuO} / \mathrm{SBA}-15$ via an ultrasonic post-grafting method and its application as a catalyst for the direct hydroxylation of benzene to phenol. Microporous Mesoporous Mater. 2013, 177, 47-53. [CrossRef]

61. Kowalczyk, A.; Borcuch, A.; Michalik, M.; Rutkowska, M.; Gil, B.; Sojka, Z.; Indyka, P.; Chmielarz, L. MCM-41 modified with transition metals by template ion-exchange method as catalysts for selective catalytic oxidation of ammonia to dinitrogen. Microporous Mesoporous Mater. 2017, 240, 9-21. [CrossRef]

62. Cirujano, F.G.; Luz, I.; Soukri, M.; Van Goethem, C.; Vankelecom, I.F.J.; Lail, M.; De Vos, D.E. Boosting the catalytic performance of metal-organic frameworks for steroid transformations by confinement within a mesoporous scaffold. Angew. Chem. Int. Ed. 2017, 56, 13302-13306. [CrossRef] [PubMed]

63. Zhang, W.; Fröba, M.; Wang, J.; Tanev, P.T.; Wong, J.; Pinnavaia, T.J. Mesoporous titanosilicate molecular sieves prepared at ambient temperature by electrostatic $\left(\mathrm{S}^{+} \mathrm{I}^{-}, \mathrm{S}^{+} \mathrm{X}^{-} \mathrm{I}^{+}\right)$and neutral $\left(\mathrm{S}^{0} \mathrm{I}^{0}\right)$ assembly pathways: A comparison of physical properties and catalytic activity for peroxide oxidations. J. Am. Chem. Soc. 1996, 118, 9164-9171. [CrossRef]

64. Che, S.; Garcia-Bennett, A.E.; Yokoi, T.; Sakamoto, K.; Kunieda, H.; Terasaki, O.; Tatsumi, T. A novel anionic surfactant templating route for synthesizing mesoporous silica with unique structure. Nat. Mater. 2003, 2, 801-805. [CrossRef] [PubMed]

65. Chen, C.-Y.; Burkett, S.L.; Li, H.-X.; Davis, M.E. Studies on mesoporous materials II. Synthesis mechanism of MCM-41. Microporous Mater. 1993, 2, 27-34. [CrossRef]

66. Singha, S.; Parida, K.M.; Dash, A.C. Fe(III)-salim anchored MCM-41: Synthesis, characterization and catalytic activity towards liquid phase cyclohexane oxidation. J. Porous Mater. 2011, 18, 707-714. [CrossRef]

67. Yang, F.; Gao, S.; Xiong, C.; Long, S.; Li, X.; Xi, T.; Kong, Y. Direct templating assembly route for the preparation of highly-dispersed vanadia species encapsulated in mesoporous MCM-41 channel. RSC Adv. 2015, 5, 72099-72106. [CrossRef]

68. Han, L.; Che, S. Anionic surfactant templated mesoporous silicas (AMSs). Chem. Soc. Rev. 2013, 42, 3740-3752. [CrossRef] [PubMed] 
69. Yokoi, T.; Yoshitake, H.; Tatsumi, T. Synthesis of anionic-surfactant-templated mesoporous silica using organoalkoxysilane-containing amino groups. Chem. Mater. 2003, 15, 4536-4538. [CrossRef]

70. Niu, K.; Dong, W.; Chen, M.; Ni, Z. Synthesis and characterization of NiO/mesoporous silica nanocomposite. Integr. Ferroelectr. 2011, 128, 135-141. [CrossRef]

71. Long, S.; Zhou, S.; Yang, F.; Lu, K.; Xi, T.; Kong, Y. An iron-based micropore-enriched silica catalyst: In situ confining of $\mathrm{Fe}_{2} \mathrm{O}_{3}$ in the mesopores and its improved catalytic properties. RSC Adv. 2016, 6, 76064-76074. [CrossRef]

72. Yang, F.; Wang, B.; Zhou, S.; Long, S.; Liu, X.; Kong, Y. Micropore-enriched CuO-based silica catalyst directly prepared by anionic template-induced method and its boosting catalytic activity in olefins epoxidation. Microporous Mesoporous Mater. 2017, 246, 215-224. [CrossRef]

73. Gao, S.; Zhou, S.; Yang, F.; Long, S.; Kong, Y. A facile method for the direct introduction of $\mathrm{FeO}_{\mathrm{x}}$ in mesoporous AMS through a templating route $\left(\mathrm{S}^{-}[\mathrm{MN}]^{+} \mathrm{I}^{-}\right)$and its catalytic application. ChemistrySelect 2016, 1, 1305-1313. [CrossRef]

74. Yang, F.; Zhou, S.; Wang, H.; Long, S.; Liu, X.; Kong, Y. A metal-assisted templating route $\left(\mathrm{S}^{0} \mathrm{M}^{+} \mathrm{I}^{-}\right)$for fabricating thin-layer $\mathrm{CoO}$ covered on the channel of nanospherical-HMS with improved catalytic properties. Dalton Trans. 2016, 45, 6371-6382. [CrossRef] [PubMed]

75. Yang, F.; Zhou, S.; Gao, S.; Liu, X.; Long, S.; Kong, Y. In situ embedding of ultra-fine nickel oxide nanoparticles in HMS with enhanced catalytic activities of styrene epoxidation. Microporous Mesoporous Mater. 2017, 238, 69-77. [CrossRef]

76. Yang, F.; Wang, B.; Zhou, S.; Yang, X.; Kong, Y. Template-induced in situ dispersion of enhanced basic-sites on sponge-like mesoporous silica and its improved catalytic property. RSC Adv. 2016, 6, 91968-91980. [CrossRef]

77. Yang, F.; Ding, Y.; Tang, J.; Zhou, S.; Wang, B.; Kong, Y. Oriented surface decoration of (Co-Mn) bimetal oxides on nanospherical porous silica and synergetic effect in biomass-derived 5-hydroxymethylfurfural oxidation. Mol. Catal. 2017, 435, 144-155. [CrossRef]

78. Betiha, M.A.; Hassan, H.M.A.; Al-Sabagh, A.M.; Khder, A.E.R.S.; Ahmed, E.A. Direct synthesis and the morphological control of highly ordered mesoporous AlSBA-15 using urea-tetrachloroaluminate as a novel aluminum source. J. Mater. Chem. 2012, 22, 17551-17559. [CrossRef]

79. Gao, F.; Zhang, Y.; Wan, H.; Kong, Y.; Wu, X.; Dong, L.; Li, B.; Chen, Y. The states of vanadium species in V-SBA-15 synthesized under different pH values. Microporous Mesoporous Mater. 2008, 110, 508-516. [CrossRef]

80. Gómez, S.; Garces, L.J.; Villegas, J.; Ghosh, R.; Giraldo, O.; Suib, S.L. Synthesis and characterization of TM-MCM-48 (TM=Mn, V, Cr) and their catalytic activity in the oxidation of styrene. J. Catal. 2005, 233, 60-67. [CrossRef]

81. Piumetti, M.; Armandi, M.; Garrone, E.; Bonelli, B. An IR spectroscopy assessment of the surface acidity of mesoporous $\mathrm{VO}_{\mathrm{x}}-\mathrm{SiO}_{2}$ catalysts. Microporous Mesoporous Mater. 2012, 164, 111-119. [CrossRef]

82. Wang, H.; Qian, W.; Chen, J.; Wu, Y.; Xu, X.; Wang, J.; Kong, Y. Spherical V-MCM-48: The synthesis, characterization and catalytic performance in styrene oxidation. RSC Adv. 2014, 4, 50832-50839. [CrossRef]

83. Zhang, Y.; Gao, F.; Wan, H.; Wu, C.; Kong, Y.; Wu, X.; Zhao, B.; Dong, L.; Chen, Y. Synthesis, characterization of bimetallic Ce-Fe-SBA-15 and its catalytic performance in the phenol hydroxylation. Microporous Mesoporous Mater. 2008, 113, 393-401. [CrossRef]

84. Wu, Y.; Zhang, Y.; Cheng, J.; Li, Z.; Wang, H.; Sun, Q.; Han, B.; Kong, Y. Synthesis, characterization and catalytic activity of binary metallic titanium and iron containing mesoporous silica. Microporous Mesoporous Mater. 2012, 162, 51-59. [CrossRef]

85. Yang, Q.; Liu, J.; Yang, J.; Kapoor, M.P.; Inagaki, S.; Li, C. Synthesis, characterization, and catalytic activity of sulfonic acid-functionalized periodic mesoporous organosilicas. J. Catal. 2004, 228, 265-272. [CrossRef]

86. Polarz, S.; Kuschel, A. Preparation of a periodically ordered mesoporous organosilica material using chiral building blocks. Adv. Mater. 2006, 18, 1206-1209. [CrossRef]

87. Alauzun, J.; Mehdi, A.; Reye, C.; Corriu, R.J.P. Direct synthesis of bifunctional mesoporous organosilicas containing chelating groups in the framework and reactive functional groups in the channel pores. J. Mater. Chem. 2007, 17, 349-356. [CrossRef]

88. Yang, X.; Zhu, F.; Huang, J.; Zhang, F.; Li, H. Phenyl@Rh(I)-bridged periodic mesoporous organometalsilica with high catalytic efficiency in water-medium organic reactions. Chem. Mater. 2009, 21, 4925-4933. [CrossRef] 
89. Huang, J.; Zhu, F.; He, W.; Zhang, F.; Wang, W.; Li, H. Periodic mesoporous organometallic silicas with unary or binary organometals inside the channel walls as active and reusable catalysts in aqueous organic reactions. J. Am. Chem. Soc. 2010, 132, 1492-1493. [CrossRef] [PubMed]

90. Corriu, R.J.P.; Mehdi, A.; Reye, C.; Thieuleux, C. Control of coordination chemistry in both the framework and the pore channels of mesoporous hybrid materials. New J. Chem. 2003, 27, 905-908. [CrossRef]

91. Zhou, S.; Wang, B.; Gao, S.; Ding, Y.; Kong, Y. The structure-property relationship of oxovanadium(IV) complexes in the wall framework of PMOs and their catalytic applications. Appl. Surf. Sci. 2017, 397, $183-191$. [CrossRef]

92. Zhang, G.; Qin, L.; Wu, Y.; Xu, Z.; Guo, X. Iron oxide nanoparticles immobilized to mesoporous $\mathrm{NH}_{2}-\mathrm{SiO}_{2}$ spheres by sulfonic acid functionalization as highly efficient catalysts. Nanoscale 2015, 7, 1102-1109. [CrossRef] [PubMed]

93. Afzal, S.; Quan, X.; Chen, S.; Wang, J.; Muhammad, D. Synthesis of manganese incorporated hierarchical mesoporous silica nanosphere with fibrous morphology by facile one-pot approach for efficient catalytic ozonation. J. Hazard. Mater. 2016, 318, 308-318. [CrossRef] [PubMed]

94. Kuwahara, Y.; Sumida, Y.; Fujiwara, K.; Yamashita, H. Facile synthesis of yolk-shell nanostructured photocatalyst with improved adsorption properties and molecular-sieving properties. Chem CatChem 2016, 8 , 2781-2788. [CrossRef]

95. Kuwahara, Y.; Yamanishi, T.; Kamegawa, T.; Mori, K.; Yamashita, H. Activity, recyclability, and stability of lipases immobilized on oil-filled spherical silica nanoparticles with different silica shell structures. Chem CatChem 2013, 5, 2527-2536. [CrossRef]

96. Kuwahara, Y.; Yamanishi, T.; Kamegawa, T.; Mori, K.; Che, M.; Yamashita, H. Lipase-embedded silica nanoparticles with oil-filled core-shell structure: Stable and recyclable platforms for biocatalysts. Chem. Commun. 2012, 48, 2882-2884. [CrossRef] [PubMed]

97. Gao, Q.; Li, H.T.; Ling, Y.; Han, B.; Xia, K.S.; Zhou, C.G. Synthesis of $\mathrm{MnSiO}_{3}$ decorated hollow mesoporous silica spheres and its promising application in environmental remediation. Microporous Mesoporous Mater. 2017, 241, 409-417. [CrossRef]

98. Wang, J.; Liu, C.; Tong, L.; Li, J.; Luo, R.; Qi, J.; Li, Y.; Wang, L. Iron-copper bimetallic nanoparticles supported on hollow mesoporous silica spheres: An effective heterogeneous fenton catalyst for orange II degradation. RSC Adv. 2015, 5, 69593-69605. [CrossRef]

99. Zhang, S.; Gai, S.; He, F.; Ding, S.; Li, L.; Yang, P. In situ assembly of well-dispersed Ni nanoparticles on silica nanotubes and excellent catalytic activity in 4-nitrophenol reduction. Nanoscale 2014, 6, 11181-11188. [CrossRef] [PubMed]

100. Zhang, Z.; Shao, C.; Sun, Y.; Mu, J.; Zhang, M.; Zhang, P.; Guo, Z.; Liang, P.; Wang, C.; Liu, Y. Tubular nanocomposite catalysts based on size-controlled and highly dispersed silver nanoparticles assembled on electrospun silica nanotubes for catalytic reduction of 4-nitrophenol. J. Mater. Chem. 2012, 22, 1387-1395. [CrossRef]

101. Jung, J.H.; Park, M.; Shinkai, S. Fabrication of silica nanotubes by using self-assembled gels and their applications in environmental and biological fields. Chem. Soc. Rev. 2010, 39, 4286-4302. [CrossRef] [PubMed]

102. Tuan, H.-Y.; Ghezelbash, A.; Korgel, B.A. Silicon nanowires and silica nanotubes seeded by copper nanoparticles in an organic solvent. Chem. Mater. 2008, 20, 2306-2313. [CrossRef]

103. Bian, S.-W.; Ma, Z.; Zhang, L.-S.; Niu, F.; Song, W.-G. Silica nanotubes with mesoporous walls and various internal morphologies using hard/soft dual templates. Chem. Commun. 2009, 1261-1263. [CrossRef] [PubMed]

104. Wang, H.; Qian, W.; Gao, S.; Du, J.; Chen, J.; Kong, Y.; Wang, J. Controllable synthesis and catalytic performance of mesoporous silica nanotube micro-reactor. Appl. Catal. A Gen. 2015, 504, 228-237. [CrossRef]

105. Wang, H.; Li, X.; Xiong, C.; Gao, S.; Wang, J.; Kong, Y. One-pot synthesis of iron-containing nanoreactors with controllable catalytic activity based on multichannel mesoporous silica. Chem CatChem 2015, 7, 3855-3864. [CrossRef]

106. Dou, J.; Zeng, H.C. Integrated networks of mesoporous silica nanowires and their bifunctional catalysis-sorption application for oxidative desulfurization. ACS Catal. 2014, 4, 566-576. [CrossRef]

107. Hoffmann, F.; Cornelius, M.; Morell, J.; Fröba, M. Silica-based mesoporous organic-inorganic hybrid materials. Angew. Chem. Int. Ed. 2006, 45, 3216-3251. [CrossRef] [PubMed] 
108. Shi, C.; Deng, S.; Wang, J.; Sun, P.; Chen, T. Hierarchically mesoporous silica single-crystalline nanorods with three dimensional cubic Fm-3m mesostructure. J. Mater. Chem. A 2013, 1, 14555-14561. [CrossRef]

109. Wang, L.-Z.; Jiang, L.; Xu, C.-C.; Zhang, J.-L. Influence of Cr-MCM-48 and Cr-KIT-6 matrixes synthesized in alkaline and acidic conditions to the visible-light driven photocatalytic performance of loaded $\mathrm{TiO}_{2}$. J. Phys. Chem. C 2012, 116, 16454-16460. [CrossRef]

110. Kumar, A.; Srinivas, D. Aminolysis of epoxides catalyzed by three-dimensional, mesoporous titanosilicates, Ti-SBA-12 and Ti-SBA-16. J. Catal. 2012, 293, 126-140. [CrossRef]

111. Kumar, A.; Srinivas, D.; Ratnasamy, P. Synthesis of framework Ti-substituted, 3-D hexagonal, mesoporous Ti-SBA-12 for selective catalytic oxidation. Chem. Commun. 2009, 6484-6486. [CrossRef] [PubMed]

112. Shi, C.; Wang, W.; Liu, N.; Xu, X.; Wang, D.; Zhang, M.; Sun, P.; Chen, T. Low temperature oxidative desulfurization with hierarchically mesoporous titaniumsilicate Ti-SBA-2 single crystals. Chem. Commun. 2015, 51, 11500-11503. [CrossRef] [PubMed]

113. Peng, R.; Zhao, D.; Dimitrijevic, N.M.; Rajh, T.; Koodali, R.T. Room temperature synthesis of Ti-MCM-48 and Ti-MCM-41 mesoporous materials and their performance on photocatalytic splitting of water. J. Phys. Chem. C 2012, 116, 1605-1613. [CrossRef]

114. Li, N.; Wang, J.-G.; Xu, J.-X.; Liu, J.-Y.; Zhou, H.-J.; Sun, P.-C.; Chen, T.-H. Synthesis of hydrothermally stable, hierarchically mesoporous aluminosilicate Al-SBA-1 and their catalytic properties. Nanoscale 2012, 4, 2150-2156. [CrossRef] [PubMed]

115. Grams, J.; Potrzebowska, N.; Goscianska, J.; Michalkiewicz, B.; Ruppert, A.M. Mesoporous silicas as supports for Ni catalyst used in cellulose conversion to hydrogen rich gas. Int. J. Hydrogen Energy 2016, 41, 8656-8667. [CrossRef]

116. Jourshabani, M.; Badiei, A.; Shariatinia, Z.; Lashgari, N.; Mohammadi Ziarani, G. Fe-supported SBA-16 type cagelike mesoporous silica with enhanced catalytic activity for direct hydroxylation of benzene to phenol. Ind. Eng. Chem. Res. 2016, 55, 3900-3908. [CrossRef]

117. Hu, L.; Yue, B.; Wang, C.; Chen, X.; He, H. Enhanced catalytic activity over vanadium-containing silylated SBA-15 catalysts for styrene epoxidation and benzene hydroxylation. Appl. Catal. A Gen. 2014, 477, 141-146. [CrossRef]

118. Khatri, P.K.; Singh, B.; Jain, S.L.; Sain, B.; Sinha, A.K. Cyclotriphosphazene grafted silica: A novel support for immobilizing the oxo-vanadium Schiff base moieties for hydroxylation of benzene. Chem. Commun. 2011, 47, 1610-1612. [CrossRef] [PubMed]

119. Kong, Y.; Xu, X.; Wu, Y.; Zhang, R.; Wang, J. Effect of promoters on the catalytic activity of MCM-41 with high copper content in benzene hydroxylation. Chin. J. Catal. 2008, 29, 385-390. [CrossRef]

120. Gao, Y.; Gao, Y.; Shi, L.; Sun, Q. Hydrothermal glucose modified C/V-SiO 2 as a reusable heterogeneous catalyst for benzene oxidation to phenol by $\mathrm{O}_{2}$. Catal. Lett. 2017, 147, 2799-2806. [CrossRef]

121. Li, B.; Wu, N.; Wu, K.; Liu, J.; Han, C.; Li, X. Bimetallic V and Ti incorporated MCM-41 molecular sieves and their catalytic properties. RSC Adv. 2015, 5, 16598-16603. [CrossRef]

122. Yamada, M.; Karlin, K.D.; Fukuzumi, S. One-step selective hydroxylation of benzene to phenol with hydrogen peroxide catalysed by copper complexes incorporated into mesoporous silica-alumina. Chem. Sci. 2016, 7, 2856-2863. [CrossRef] [PubMed]

123. Aratani, Y.; Yamada, Y.; Fukuzumi, S. Selective hydroxylation of benzene derivatives and alkanes with hydrogen peroxide catalysed by a manganese complex incorporated into mesoporous silica-alumina. Chem. Commun. 2015, 51, 4662-4665. [CrossRef] [PubMed]

124. Yang, Y.; Ding, J.; Wang, B.; Wu, J.; Zhao, C.; Gao, G.; Wu, P. Influences of fluorine implantation on catalytic performance and porosity of MOR-type titanosilicate. J. Catal. 2014, 320, 160-169. [CrossRef]

125. Han, B.; Wang, H.; Kong, Y.; Wang, J. Improvement on the mesostructural ordering and catalytic activity of Co-MCM-41 with ascorbic acid as auxiliary. Mater. Lett. 2013, 100, 159-162. [CrossRef]

126. Sanjini, N.S.; Velmathi, S. Cuo impregnated mesoporous silica KIT-6: A simple and efficient catalyst for benzene hydroxylation by $\mathrm{C}-\mathrm{H}$ activation and styrene epoxidation reactions. J. Porous Mater. 2016, 23, 1527-1535. [CrossRef]

127. Chen, X.; Zhao, W.; Wang, F.; Xu, J. Preparation and characterization of vanadium(IV) oxide supported on SBA-15 and its catalytic performance in benzene hydroxylation to phenol using molecular oxygen. J. Nat. Gas Chem. 2012, 21, 481-487. [CrossRef] 
128. Samran, B.; Aungkutranont, S.; White, T.J.; Wongkasemjit, S. Room temperature synthesis of Ti-SBA-15 from silatrane and titanium-glycolate and its catalytic performance towards styrene epoxidation. J. Sol-Gel Sci. Technol. 2011, 57, 221-228. [CrossRef]

129. Fadhli, M.; Khedher, I.; Fraile, J.M. Modified Ti/MCM-41 catalysts for enantioselective epoxidation of styrene. J. Mol. Catal. A Chem. 2016, 420, 282-289. [CrossRef]

130. Cui, H.; Zhang, Y.; Zhao, L.; Zhu, Y. Adsorption synthesized cobalt-containing mesoporous silica SBA-15 as highly active catalysts for epoxidation of styrene with molecular oxygen. Catal. Commun. 2011, 12, 417-420. [CrossRef]

131. Yang, G.; Chen, X.; Wang, X.; Xing, W.; Xu, N. Nickel(II) complex anchored on MCM-41 for the epoxidation of styrene by oxygen. Chin. J. Catal. 2013, 34, 1326-1332. [CrossRef]

132. Qi, B.; Lou, L.-L.; Wang, Y.; Yu, K.; Yang, Y.; Liu, S. Comparison of different prepared Mn-MCM-41 catalysts in the catalytic epoxidation of alkenes with 30\% $\mathrm{H}_{2} \mathrm{O}_{2}$. Microporous Mesoporous Mater. 2014, 190, $275-283$. [CrossRef]

133. Rahman, S.; Farooqui, S.A.; Rai, A.; Kumar, R.; Santra, C.; Prabhakaran, V.C.; Bhadu, G.R.; Sen, D.; Mazumder, S.; Maity, S.; et al. Mesoporous TUD-1 supported indium oxide nanoparticles for epoxidation of styrene using molecular $\mathrm{O}_{2}$. RSC Adv. 2015, 5, 46850-46860. [CrossRef]

134. Li, B.; Luo, X.; Zhu, Y.; Wang, X. Immobilization of $\mathrm{Cu}(\mathrm{II})$ in KIT-6 supported $\mathrm{Co}_{3} \mathrm{O}_{4}$ and catalytic performance for epoxidation of styrene. Appl. Surf. Sci. 2015, 359, 609-620. [CrossRef]

135. Li, B.; Luo, X.; Huang, J.; Wang, X.; Liang, Z. One-pot synthesis of ordered mesoporous Cu-KIT-6 and its improved catalytic behavior for the epoxidation of styrene: Effects of the $\mathrm{pH}$ value of the initial gel. Chin. J. Catal. 2017, 38, 518-528. [CrossRef]

136. Mandal, S.; Rahman, S.; Kumar, R.; Bando, K.K.; Chowdhury, B. XAFS, XPS characterization of cerium promoted Ti-TUD-1 catalyst and it's activity for styrene oxidation reaction. Catal. Commun. 2014, 46, $123-127$. [CrossRef]

137. Wang, J.; Lu, J.; Yang, J.; Chen, R.; Zhang, Y.; Yin, D.; Wang, J. Ti containing mesoporous silica submicrometer-sphere, with tunable particle size for styrene oxidation. Appl. Surf. Sci. 2013, 283, 794-801. [CrossRef]

138. Li, B.; Zhu, Y.; Jin, X. Synthesis of cobalt-containing mesoporous catalysts using the ultrasonic-assisted "pH-adjusting" method: Importance of cobalt species in styrene oxidation. J. Solid State Chem. 2015, 221, 230-239. [CrossRef]

139. Yang, C.; Fu, L.; Zhu, R.; Liu, Z. Influence of cobalt species on the catalytic performance of Co-N-C/SiO 2 for ethylbenzene oxidation. Phys. Chem. Chem. Phys. 2016, 18, 4635-4642. [CrossRef] [PubMed]

140. Fu, L.; Zhao, S.; Chen, Y.; Liu, Z. One-pot synthesis of mesoporous silica hollow spheres with Mn-N-C integrated into the framework for ethylbenzene oxidation. Chem. Commun. 2016, 52, 5577-5580. [CrossRef] [PubMed]

141. Bhoware, S.S.; Shylesh, S.; Kamble, K.R.; Singh, A.P. Cobalt-containing hexagonal mesoporous molecular sieves (Co-HMS): Synthesis, characterization and catalytic activity in the oxidation reaction of ethylbenzene. J. Mol. Catal. A Chem. 2006, 255, 123-130. [CrossRef]

142. Jermy, B.R.; Kim, S.Y.; Kim, D.K.; Park, D.W. Optimization of key parameters for effective vanadium substitution into cubic SBA-16 in the presence of co-surfactant at low acidity: Application in the selective oxidation of ethylbenzene. J. Ind. Eng. Chem. 2011, 17, 130-137. [CrossRef]

143. Li, S.; Zhai, S.-R.; An, Q.-D.; Li, M.-H.; Song, Y.; Song, X.-W. Designed synthesis of multifunctional $\mathrm{Fe}_{3} \mathrm{O}_{4} @ \mathrm{SiO}_{2}-\mathrm{NH}_{2} @ \mathrm{Cs}-\mathrm{Co}(\mathrm{II})$ towards efficient oxidation of ethylbenzene. Mater. Res. Bull. 2014, 60, 665-673. [CrossRef]

144. Imran, G.; Pachamuthu, M.P.; Maheswari, R.; Ramanathan, A.; Sardhar Basha, S.J. Catalytic activity of MnTUD-1 for liquid phase oxidation of ethylbenzene with tert-butyl hydroperoxide. J. Porous Mater. 2012, 19, 677-682. [CrossRef]

145. Dapurkar, S.E.; Kawanami, H.; Yokoyama, T.; Ikushima, Y. Solvent-free selective oxidation of benzylic compounds over chromium containing mesoporous molecular sieve catalyst at $1 \mathrm{~atm} \mathrm{O}_{2}$. Catal. Commun. 2009, 10, 1025-1028. [CrossRef]

146. Ghiaci, M.; Molaie, F.; Sedaghat, M.E.; Dorostkar, N. Metalloporphyrin covalently bound to silica. Preparation, characterization and catalytic activity in oxidation of ethyl benzene. Catal. Commun. 2010, 11, 694-699. [CrossRef] 
147. Liu, M.; Xiao, Z.; Dai, J.; Zhong, W.; Xu, Q.; Mao, L.; Yin, D. Manganese-containing hollow TS-1: Description of the catalytic sites and surface properties for solvent-free oxidation of ethylbenzene. Chem. Eng. J. 2017, 313, 1382-1395. [CrossRef]

148. Sujandi; Prasetyanto, E.A.; Han, D.-S.; Lee, S.-C.; Park, S.-E. Immobilization of Co(III) using tethered cyclam ligand on SBA-15 mesoporous silica for aerial oxidation of ethylbenzene. Catal. Today 2009, 141, 374-377. [CrossRef]

149. Ma, H.; Xu, J.; Chen, C.; Zhang, Q.; Ning, J.; Miao, H.; Zhou, L.; Li, X. Catalytic aerobic oxidation of ethylbenzene over Co/SBA-15. Catal. Lett. 2007, 113, 104-108. [CrossRef]

150. Parida, K.M.; Dash, S.S. Manganese containing MCM-41: Synthesis, characterization and catalytic activity in the oxidation of ethylbenzene. J. Mol. Catal. A Chem. 2009, 306, 54-61. [CrossRef]

151. Vetrivel, S.; Pandurangan, A. Side-chain oxidation of ethylbenzene with tert-butylhydroperoxide over mesoporous Mn-MCM-41 molecular sieves. J. Mol. Catal. A Chem. 2004, 217, 165-174. [CrossRef]

152. Visuvamithiran, P.; Shanthi, K.; Palanichamy, M.; Murugesan, V. Direct synthesis of Mn-Ti-SBA-15 catalyst for the oxidation of ethylbenzene. Catal. Sci. Technol. 2013, 3, 2340-2348. [CrossRef]

153. Pachamuthu, M.P.; Rajalakshmi, R.; Maheswari, R.; Ramanathan, A. Direct glycol assisted synthesis of an amorphous mesoporous silicate with framework incorporated $\mathrm{Co}^{2+}$ : Characterization and catalytic application in ethylbenzene oxidation. RSC Adv. 2014, 4, 29909-29916. [CrossRef]

154. Gago, S.; Bruno, S.M.; Queirós, D.C.; Valente, A.A.; Gonçalves, I.S.; Pillinger, M. Oxidation of ethylbenzene in the presence of an MCM-41-supported or ionic liquid-standing bischlorocopper(II) complex. Catal. Lett. 2011, 141, 1009-1017. [CrossRef]

155. Jiang, S.; Kong, Y.; Wang, J.; Ren, X.; Yan, Q. Synthesis, characterization of bimetallic Sn-Zn-MCM41 and its catalytic performance in the hydroxylation of phenol. J. Porous Mater. 2006, 13, 341-346. [CrossRef]

156. Wang, X.; Xu, H.; Fu, X.; Liu, P.; Lefebvre, F.; Basset, J.-M. Characterization and catalytic properties of tin-containing mesoporous silicas prepared by different methods. J. Mol. Catal. A Chem. 2005, 238, 185-191. [CrossRef]

157. Zhang, H.; Tang, C.; Lv, Y.; Sun, C.; Gao, F.; Dong, L.; Chen, Y. Synthesis, characterization, and catalytic performance of copper-containing SBA-15 in the phenol hydroxylation. J. Colloid Interface Sci. 2012, 380, 16-24. [CrossRef] [PubMed]

158. Parida, K.M.; Rath, D. Surface characterization and catalytic evaluation of copper-promoted Al-MCM-41 toward hydroxylation of phenol. J. Colloid Interface Sci. 2009, 340, 209-217. [CrossRef] [PubMed]

159. Chaliha, S.; Bhattacharyya, K.G. Using Mn(II)-MCM41 as an environment-friendly catalyst to oxidize phenol, 2-chlorophenol, and 2-nitrophenol in aqueous solution. Ind. Eng. Chem. Res. 2008, 47, 1370-1379. [CrossRef]

160. Hong, L.; Guanzhong, L.; Yanglong, G.; Yun, G.; Junsong, W. Synthesis of framework-substituted Fe-HMS and its catalytic performance for phenol hydroxylation. Nanotechnology 2006, 17, 997.

161. Choi, J.-S.; Yoon, S.-S.; Jang, S.-H.; Ahn, W.-S. Phenol hydroxylation using Fe-MCM-41 catalysts. Catal. Today 2006, 111, 280-287. [CrossRef]

162. Andas, J.; Adam, F.; Rahman, I.A. Sol-gel derived mesoporous cobalt silica catalyst: Synthesis, characterization and its activity in the oxidation of phenol. Appl. Surf. Sci. 2014, 315, 154-162. [CrossRef]

163. He, H.; Gao, F.; Gao, S.; Wang, H.; Liu, X.; Dong, L.; Kong, Y. The synergistic effect of bimetallic Zn-Ti in MCM-41 support for the improvement of catalytic activity. J. Nanosci. Nanotechnol. 2016, 16, 7742-7749. [CrossRef]

164. Xia, M.; Long, M.; Yang, Y.; Chen, C.; Cai, W.; Zhou, B. A highly active bimetallic oxides catalyst supported on Al-containing MCM-41 for fenton oxidation of phenol solution. Appl. Catal. B Environ. 2011, 110, 118-125. [CrossRef]

165. Zhong, W.; Kirk, S.R.; Yin, D.; Li, Y.; Zou, R.; Mao, L.; Zou, G. Solvent-free selective oxidation of toluene by oxygen over $\mathrm{MnO}_{\mathrm{x}} / \mathrm{SBA}-15$ catalysts: Relationship between catalytic behavior and surface structure. Chem. Eng. J. 2015, 280, 737-747. [CrossRef]

166. Liu, C.-C.; Lin, T.-S.; Chan, S.I.; Mou, C.-Y. A room temperature catalyst for toluene aliphatic C-H bond oxidation: Tripodal tridentate copper complex immobilized in mesoporous silica. J. Catal. 2015, 322, 139-151. [CrossRef]

167. Szegedi, Á.; Popova, M.; Minchev, C. Catalytic activity of Co/MCM-41 and Co/SBA-15 materials in toluene oxidation. J. Mater. Sci. 2009, 44, 6710. [CrossRef] 
168. Suh, M.-J.; Ihm, S.-K. Preparation of copper oxide with high surface area associated with mesoporous silica. Top. Catal. 2010, 53, 447-454. [CrossRef]

169. Li, W.B.; Zhuang, M.; Xiao, T.C.; Green, M.L.H. MCM-41 supported Cu-Mn catalysts for catalytic oxidation of toluene at low temperatures. J. Phys. Chem. B 2006, 110, 21568-21571. [CrossRef] [PubMed]

170. Qu, Z.; Bu, Y.; Qin, Y.; Wang, Y.; Fu, Q. The effects of alkali metal on structure of manganese oxide supported on SBA-15 for application in the toluene catalytic oxidation. Chem. Eng. J. 2012, 209, 163-169. [CrossRef]

171. Popova, M.; Szegedi, Á.; Cherkezova-Zheleva, Z.; Mitov, I.; Kostova, N.; Tsoncheva, T. Toluene oxidation on titanium- and iron-modified MCM-41 materials. J. Hazard. Mater. 2009, 168, 226-232. [CrossRef] [PubMed]

172. Cánepa, A.L.; Elías, V.R.; Vaschetti, V.M.; Sabre, E.V.; Eimer, G.A.; Casuscelli, S.G. Selective oxidation of benzyl alcohol through eco-friendly processes using mesoporous V-MCM-41, Fe-MCM-41 and Co-MCM-41 materials. Appl. Catal. A Gen. 2017, 545, 72-78. [CrossRef]

173. Cang, R.; Lu, B.; Li, X.; Niu, R.; Zhao, J.; Cai, Q. Iron-chloride ionic liquid immobilized on SBA-15 for solvent-free oxidation of benzyl alcohol to benzaldehyde with $\mathrm{H}_{2} \mathrm{O}_{2}$. Chem. Eng. Sci. 2015, 137, 268-275. [CrossRef]

174. Rana, B.S.; Jain, S.L.; Singh, B.; Bhaumik, A.; Sain, B.; Sinha, A.K. Click on silica: Systematic immobilization of $\mathrm{Co}$ (II) Schiff bases to the mesoporous silica via click reaction and their catalytic activity for aerobic oxidation of alcohols. Dalton Trans. 2010, 39, 7760-7767. [CrossRef] [PubMed]

(C) 2018 by the authors. Licensee MDPI, Basel, Switzerland. This article is an open access article distributed under the terms and conditions of the Creative Commons Attribution (CC BY) license (http:/ / creativecommons.org/licenses/by/4.0/). 